\title{
Development of Permanent Artificial Bowel Replacement Substrates
}

\author{
Kantida Koysombat ${ }^{1}$ \& Atikah Haneef ${ }^{1 *}$ \\ ${ }^{1}$ Institute of Life Course and Medical Sciences, The University of Liverpool, Liverpool, United \\ Kingdom \\ *correspondence to: atikahh@liverpool.ac.uk
}

Keywords: Electrospinning, bowel replacement, TESI, tissue engineering, small intestine.

\section{British English used throughout manuscript}

\begin{abstract}
Short bowel syndrome (SDS) is a malabsorption disorder caused by loss of function of the small intestine, either by trauma or innately. Current treatment options include parenteral nutrition (PN) or allograft transplants. Long term PN dependence can lead to complications due to line infections and toxicity from the formula itself. A lack of healthy donors results in long waiting lists and high mortality rates. With allograft transplants, long-term graft and patient survival rates are poor ( $48 \%$ and $39 \%$ respectively at 5 years); graft loss occurs due to rejection (48\%), thrombosis (28\%), sepsis (12\%); main causes of death are due to bacterial infection (94\%) and rejection. Costs associated with PN annually per patient approximate to $£ 40,000$, whereas one allograft procedure costs approximately $£ 80,000$; not including intervention due to complications.

Interest in developing an off-the-shelf bioengineered alternative have been expressed. Autologous transplants could be a more beneficial route to improving survival rates, enabling the transplant of patients' healthy cells back to them. We describe here the development of a synthetic poly(ethylene terephthalate) scaffold using electrospinning, which showed excellent physical and chemical characteristics; high surface area:volume ratio, high mechanical strength, high porosity, and the ability to be chemically/physically functionalised without losing integrity in structure and physical properties. The cost of electrospinning is far lower in comparison to the current available treatment options, potentially providing a stable, off-the-shelf, ready-to-culture product as the need arises for applications in tissue engineered small intestine (TESI), or 3D models for small bowel research.
\end{abstract}

\section{Introduction}

Short bowel syndrome is a malabsorption disorder which occurs due to the physical loss or the loss of function of a portion of the small intestine, either at birth or after surgery (Tappenden 2014). Current treatment options include parenteral nutrition (PN) or allograft transplants. Long term PN dependence can lead to complications due to line infections and toxicity from the formula itself. A lack of healthy donors results in long waiting lists and high mortality rates worldwide (Schalamon, Johannes et al. 2004). With allograft transplants, long-term graft and patient survival rates are poor (48\% and $39 \%$ respectively at 5 years) (SJ Middleton et al 2004); graft loss occurs due to rejection (48\%), thrombosis (28\%), sepsis $(12 \%)$; main causes of death are due to bacterial infection (94\%) and rejection. Costs 
associated with PN annually per patient approximate to $f 40,000$, whereas one allograft procedure costs approximately $f 80,000$; not including intervention due to complications.(Bharadwaj et al 2017)

Therefore, development of a synthetic bowel substrate which can be readily available as an off-the-shelf product has been proposed. The principal of bowel tissue engineering consists of seeding autologous cells onto a synthetic scaffold, followed by in vitro tissue maturation and ultimately implanting the construct into the host environment (Lanza, Langer et al. 2007). The specific physical properties of bowel substrates that are crucial for the success of this approach are biocompatibility, regulated permeability and suitable mechanical properties allowing the material to withstand peristaltic actions. The scaffold should aim to mimic in vivo microenvironments of the targeted extracellular matrix (ECM) by replicating biochemical, biomechanical and topographical cues to regulate specific cellular response.

Basement membrane (BM) is a form of ECM that provides anchorage to cells and separates epithelium from underlying lamina propria (Vancamelbeke and Vermeire, 2017). Naturally, it is composed of 4 main proteins, including laminin, type IV collagen, the glycoprotein nidrogen and the heparan sulfate proteoglycan perlecan and carbohydrate polymers such as glycosaminoglycans (Mak and Mei, 2017). One of the most notable examples of BMs is in the intestine. Gut BM plays a crucial role as a semipermeable barrier and is highly responsive to both internal and exogenous stimuli. The dynamic interaction between structural components allow selective nutrient absorption while preventing transportation of harmful antigens and microorganisms (Vancamelbeke and Vermeire, 2017). Such complexity poses a challenge to the construction of a much-needed artificial bowel replacement substrate.

In this work, electrospun poly(ethylene terephthalate) (PET) was studied. PET is a type of nondegradable polyester, formed from condensation polymerisation of ester monomers which is a product from the reaction between ethylene glycol and terephthalic acid (Clark, 2004) (Figure 1). It is widely used as plastics in food packaging and is FDA-approved (Custom-Pak, 2018). PET has desirable characteristics for tissue engineering such as biocompatibility, high tensile strength, chemical resistance and low cost (Subramaniam and Sethuraman, 2014). Existing literature shows promising results on PET as it already has successful biomedical applications such as in large vascular grafts and anterior cruciate ligament prosthesis (Subramaniam and Sethuraman, 2014).

Electrospinning has gained significant popularity in the biomaterials field due to its simplicity and capability to extrude non-woven nanoscale fibres, allowing formation of polymeric membranes at a relatively low cost (Vass et al 2019). Electrospinning is initiated by application of electrostatic force to a droplet of liquid via high voltage supply. Once above a threshold voltage, the spherical droplet will elongate until it erupts into a conical shape referred to as Taylor cone (Agrahari et al., 2017). The electrostatic force overcomes the droplet surface tension, resulting in the extrusion of a charged liquid jet towards the grounded collector. The jet initially accelerates in a straight line but subsequently adapts a vigorous whipping motion which stretches and thins the resultant fibre. En route from the syringe tip to the collector, solvent in the polymer jet solution evaporates and fibres form a non-woven membrane on the collector surface (Xue et al., 2017). Fibre characteristics are 
influenced by multiple parameters that can be modified to suit its intended purpose, thereby rendering this technique as highly versatile and suitable for industrial-scale production (Kajdič et al., 2018). Spun fibres possess novel properties such as extremely high surface area-to-volume ratio, neat morphology and interconnected voids. These features propose electrospun membrane as the prime candidate for cell carrier scaffold due to its structural resemblance to natural extracellular matrix (ECM)(Jun et al., 2018) and its ability to promote native morphology and function in seeded fibroblast cell lines and small intestine organoids (Grikscheit et al 2004).

This article describes the optimisation process of an electrospun membrane and evaluation of its physical properties after various surface functionalisation treatments. The material discussed has the potential to be used as a permanent cell-carrier substrate that could contribute to the development of TESI, or for application in 3D models for small bowel research.

\section{Material and methods}

\section{Fabrication of PET fibre scaffolds}

All experiments were undertaken in a custom-built grounded fume-hood using a custombuilt electrospinning rig (Figure 2). Pellets of PET (Polysciences Inc, USA) were dissolved in 1,1,1,3,3,3-hexafluoro-2-propanol (HFIP; Apollo Scientific, UK) at concentrations of 25\%, $20 \%, 15 \%$ and $10 \%(\mathrm{w} / \mathrm{v})$. After stirring for 24 hours at room temperature to ensure homogeneity, the polymer solution was introduced into a $10 \mathrm{ml}$ syringe (BD Plastipak) and mounted onto a mechanical syringe pump to control the solution flow rate. A high-voltage power supply was used to apply a range of potential to the syringe. The electrospun fibre was deposited onto a grounded collector placed at various distances. All spinning parameters were summarised in TABLES 1 and 2.

Three membranes were electrospun for each parameter $(n=3)$ except for $10 \%(w / v)$ at tipto-collector distance of $10 \mathrm{~cm}$ where two membranes were fabricated $(n=2)$.

\section{Preparation of fibres for SEM}

The surface morphology of the electrospun fibrous membrane was examined by scanning electron microscopy (SEM). Samples were attached to SEM stubs using carbon adhesive discs and then coated with $10 \mathrm{~nm}$ of platinum using a Q150T (QuorumTechnologies, Laughton, UK). Secondary electron SEM imaging was performed in a Quanta $250 \mathrm{FEG}$ (FEI, Hillsboro, Oregon, USA) at low vacuum ( 0.53 Torr) with an acceleration voltage of $5 \mathrm{kV}$. Membranes were scanned at 5,000x and 10,000x magnifications. Images were analysed using Image digital analysis software to measure the diameters of the individual fibres. A total of 50 measurements were taken at random and average fibre diameter calculated. Three membranes were analysed for each parameter $(n=150)$ A fibre diameter distribution histogram was plotted using GraphPad Prism 8.3.0.

\section{Mechanical testing of electrospun membranes}

Quantitative analysis: tensile testing 
Electrospun membranes were measured for tensile strength using a uniaxial tension/compression tester (Univert, CellScale) equipped with $1 \mathrm{~N}$ load cell (Futek, California, USA) at a displacement rate of $2 \mathrm{~mm}$ per minute. Membranes were manually cut into dog-bone shapes (Figure 3.i) to ensure the concentration of stress is in the middle of the sample when subjected to tensile force. The strips were subsequently mounted onto paper frames and the shoulder section taped down at each end. The paper frames were cut before tensile force applied. Membranes were tested until failure or for a maximum of 10 minutes, whichever came first. A digital calliper (Duratool) was used to measure the crosssectional area of the fibre; these were used to calculate stress and strain. The gradient of the elastic region in the stress $v$ strain curve (Figure 3.ii) equates to the tensile strength of the membrane.

Qualitative analysis: manual handling

Membranes were folded, rolled and twisted to determine practicality of manual handling and observations noted.

\section{Thickness and porosity}

Membranes were cut into approximately $1 \mathrm{~cm}^{2}$ squares, thickness measured using a digital calliper (Duratool), and then weighed. Both measurements were performed three times on each membrane $(n=3)$ and the porosity calculated using the following equation (Haneef and Downes, 2015):

$$
\text { Porosity (\%) }=[1-(\text { apparent density/bulk density) }] \times 100
$$

Where apparent density $\left(\mathrm{g} / \mathrm{cm}^{3}\right)=[$ mat mass $(\mathrm{g}) /$ mat thickness $(\mathrm{cm})] \times$ mat area $\left(\mathrm{cm}^{2}\right)$.

Bulk density of PET was taken as $1.4 \mathrm{~g} / \mathrm{cm}^{3}$.

\section{Contact angle measurements before and after surface treatment}

Water contact angle (WCA) was measured using a drop shape analyser (DSA100, Krüss, Hamburg, Germany). Three surfaces were analysed, including: tissue culture plastic as positive control, planar polymer surface and electrospun membrane. Planar polymer surfaces were fabricated by casting the polymer solution in a glass culture dish and left to evaporate overnight under fumehood flow to form a sheet. WCA was measured using a sessile drop method. A drop of $5 \mu l$ distilled water was placed on the surface. Young's contact angle was subsequently measured from an image of the sessile drop using Krüss Drop Shape Analysis software. The angle was obtained at the three-phase boundary line between solid (membrane), liquid (water drop) and gas (air). All the WCA data were an average of three measurements at different locations on the surface $(n=3)$.

\section{Scaffold surface treatments}

Multiple surface treatment modalities have been used in this study for biofunctionalization, particularly chemical and biological modifications including: ultraviolet (UV) irradiation, wet chemical methods and physical adsorption (Supplementary Figure 1).

\subsection{UV treatment}


The scaffold was positioned at a distance of $30 \mathrm{~mm}$ relative to the UV source (UVP CL-1000 Ultraviolet Crosslinker) and irradiated at the wave of $254 \mathrm{~nm}$ and energy of $15 \mathrm{~mJ} \mathrm{~cm}$ for 15 or 30 minutes. Only one side of the membrane was treated; this was marked on the membrane to enable further characterisation of the treated side.

\subsection{Wet chemical and protein treatment}

Two incubation time points (15 and 30 minutes) and two concentrations of sodium hydroxide $(\mathrm{NaOH})$ solution $(0.1 \mathrm{M}$ and $1 \mathrm{M}$; Sigma) were examined. Electrospun PET membranes were fully submerged in $\mathrm{NaOH}$ solution at room temperature for the desired treatment time. The PET membranes were then washed three times in deionised water and left to dry on a non-stick sheet in laboratory conditions.

The same method was repeated for hydrochloric acid $(\mathrm{HCl})$ solution (0.1 $\mathrm{M}$ and $1 \mathrm{M}$; Sigma), and fetal calf serum (FCS) diluted in PBS at 1 in 10 concentration and neat (LabTech).

\section{SEM of membranes after surface treatment}

$10 \times 10 \mathrm{~mm}$ PET membrane samples were attached to SEM stubs using carbon adhesive discs and then coated with chromium to reduce charging. SEM imaging was performed in a Hitachi S4800 high resolution SEM with an acceleration voltage of $2 \mathrm{kV}$. Membranes were scanned at 2,500x, 10,000x and 50,000x magnifications.

\section{Mechanical testing of electrospun membranes after surface treatment}

Identical setup to the tensile testing of membranes before surface treatment. Membranes were subjected to 10 cycles of 5 seconds of $0.3 \mathrm{~mm}$ displacement and 5 seconds of recovery, followed by stretch at a displacement rate of $3 \mathrm{~mm}$ per minute for a maximum of 10 minutes or until failure, which ever came first. A digital calliper (Duratool) was used to measure the cross-sectional area of the fibre; these were used to calculate stress and strain. The gradient of the elastic region in the stress versus strain curve equates to the Young's modulus of the membrane. Three membranes were tested for each treatment condition $(n=3)$

\section{Fourier Transform Infrared Spectroscopy (FTIR)}

PET membranes were analysed using the diamond detector in the attenuated total reflection Fourier transform infrared spectroscopy (ATR-FTIR) (Bruker Vertex V70 FT-IR Spectrometer). The ATR-FTIR spectra were recorded between 400 and $4000 \mathrm{~cm}^{-1}$ and the 'Peak Picking' tool was used to identify peaks.

\section{Permeability assay}

A permeability assay measures the fluorescence intensity of fluorescein isothiocyanate (FITC) permeating through the PET membranes (Yeste et al. 2018). Untreated membranes and membrane treated with $1 \mathrm{M} \mathrm{NaOH}$ for 30 minutes was mounted on cell-crowns and submerged in $800 \mu \mathrm{l}$ of deionised water in a 24 well-plate. Subsequently $100 \mu \mathrm{l}$ of 1:10000 
( $0.0185 \mathrm{mmol}$ ) FITC was pipetted onto the membrane, and the membranes were covered with foil and left for 10, 30 and 60 minutes. After the desired time point, three samples of the permeated FITC solution from each treatment group were pipetted into a 96 well-plate and analysed using the BMG FLUOstar OPTIMA Microplate Reader. Gain adjustment were performed to the fluorescence reading and converted into FITC concentration.

\section{Statistical analysis}

All statistical analysis was performed using GraphPad Prism 8.4.1 for Windows. Datasets were checked for normality using the Shapiro-Wilk test and statistical test performed accordingly. Data is presented as mean \pm standard deviation. Statistical significance was taken at two-sided p-values of $<0.05$.

\section{Results and Discussion}

\section{Fibre morphology and fibre diameter}

\section{Qualitative analysis}

Increase in fibre homogeneity with increase in polymer concentration was observed. Micrographs revealed the structural development from aligned arrays of smooth, continuous electrospun fibres at $25 \%(\mathrm{w} / \mathrm{v})$ to beads on a string morphology at $15-20 \%(\mathrm{w} / \mathrm{v})$ and distinct beading at $10 \%(\mathrm{w} / \mathrm{v})$ (Figure 4.i.) As polymer concentration increased, the diameter of beads and distance between them increased. In addition, the beads transformed from spherical to ellipse-like shape (Figure 4.i.B and Figure 4.i.D). These findings are consistent with existing literature and can be explained by polymer concentration, solution viscoelasticity and surface tension. Polymer concentration is directly proportional to solution viscoelasticity while surface tension depends on the nature of the polymer and solvent used (Fong et al., 1999). Due to surface tension, liquids display PlateauRayleigh instability to minimise their surface area; shrinking from streamline jets to sphere droplets (Haefner et al., 2015). Yu et al postulated that if viscoelastic forces of the polymer overcome surface tension then smooth fibres will be formed (Yu et al., 2006). Since the polymer and solvent used in this study and in turn the surface tension was kept constant, the degree of beading could be attributed to polymer concentration.

Qualitative analysis of the SEM images showed that the fibre morphology was not affected by some operation parameters (Supplementary Figure 2). Experimental observations illustrated that membranes collected at $30 \mathrm{~cm}$ was significantly thinner and delicate compared to those collected at $10 \mathrm{~cm}$; membranes collected at $10 \mathrm{~cm}$ were difficult to handle as it had the tendency to stick onto itself. Further, the proportions of the PET membrane sheet formed on the collector surface after the electrospinning process was also different. The size of the membrane sheet considerably decreased when the tip-to-collector distance decreased and became more circular in shape; corresponding with findings from Hekmati et al (Hekmati et al., 2013).

\section{Quantitative analysis}

In general, fibre diameter was found to increase with polymer concentration (Figure 4.ii). This is due to higher output of polymer extruded at any one time with higher 
concentrations. However, fibres obtained from $10 \%(\mathrm{w} / \mathrm{v})$ membranes had a larger average diameter than $15 \%$ and $20 \%(\mathrm{w} / \mathrm{v})$ fibres as well as bigger standard deviation. As aforementioned, low solution concentration and therefore low viscoelasticity led to unstable electrospinning, resulting in high variation of electrospun fibres. In addition, $10 \%$ $(w / v)$ fibre diameters showed bimodal distribution (Figure 4.iii) therefore the mean may not be representative of the whole population. No significant relationship between tip-tocollector distance and fibre diameter could be concluded. This finding is in contrast with previous literature which reported a positive correlation and stated the increase in the needle-tip-to-collector distance allows the polymer solution jet to bend and whip more extensively, thus decreasing fibre diameter (Mazoochi et al., 2012).

Solution flow rate of $1 \mathrm{ml} / \mathrm{hr}$ significantly reduced fibre diameter. ANOVA analysis of the flow rate parameter showed significant difference among means $(F=8.232$, $\mathrm{df}=599$, $\mathrm{p}<0.0001$ ) and Tukey post hoc analysis illustrated that fibres spun at $1 \mathrm{ml} / \mathrm{hr}$ had significantly smaller diameter than those spun at other flow rates. However, other flow rates did not display significant differences (TABLE 3). Flow rate directly influenced the amount of solution present at the syringe tip at any one time; therefore, low flow rate means less extrusion of polymer solution, resulting in small diameter.

Interestingly, spinning voltage, solution flow rate and collection time did not affect fibre morphology or fibre diameter. This is inconsistent with existing literature that states spinning voltage directly influences the stretching force of the polymer jet, which in turn regulates thinning of the jet (Lee et al., 2004, Buchko et al., 1999). Hence, an increase in voltage leads to thinner fibres. However, Zhao et al. demonstrated that beyond a threshold value, high voltage may result in thicker fibres due to reduction in flight time (Zhao et al., 2004). Multiple groups have reported an increase in fibre diameter with increase in solution flow rate since there is an increase in volume of polymer being syringed out at any one time (Zargham et al., 2012, Milleret et al., 2011). Further, an increase in flow rate may imply emergence of secondary jets; during the electrospinning process, the initial jet can solidify in certain places on the nozzle tip, leading to eruption of multiple secondary jets from unsolidified areas. These secondary jets each contain smaller volumes of polymer solution than the initial jet, resulting in smaller fibres (De Schoenmaker et al., 2012). This phenomenon was observed during electrospinning in our study. Additionally, increase in collection time may increase the possibility of solidification of the initial jet, leading to a decrease in the average fibre diameter.

Effect of environmental parameters of temperature and humidity was tested on $25 \%(\mathrm{w} / \mathrm{v})$ PET membranes because it showed defect-free fibre morphology at standard laboratory conditions. Temperature and humidity did not affect fibre morphology and fibres were defect-free (Figure 4.iv). However, larger fibre diameters were produced when the temperature was high and humidity was low. Unpaired t-test of fibre diameters showed significant difference between means of $0.211 \pm 0.0578(\mathrm{~F}=1.001, \mathrm{df}=298, \mathrm{p}$-value $=$ $0.0003)$. This indicated fibres spun at high temperature and low humidity have significantly larger average diameter. Currently, there is contradicting evidence in literature on the effect of temperature and humidity on fibre diameter. Wang et al. (Wang et al., 2007) reported that temperature elevation was an effective method to produce ultrathin fibres whilst works from Guangzhi et al. (Guangzhi et al., 2017) suggested that excessively high 
temperature can lead to large fibres. Higher humidity resulted in larger polystyrene fibre diameter (Kim et al., 2004), but Htike et al. (Htike et al., 2012) demonstrated fibres were thinner instead. These inconsistent findings may be attributed to multiple competing factors on the electrospinning process. An increase in temperature will decrease solution viscosity and surface tension (Guangzhi et al., 2017), resulting in smaller fibres. Low humidity can lead to reduction in precipitation of the polymer when water condenses on the surface of the polymer jet, resulting in thinner fibres (Ogulata and İçoğlu, 2013). Both high temperature and low humidity directly accelerate solvent evaporation from fluid jets. Premature evaporation can lead to reduced stretching of the polymer fluid jet, thus fibres with large diameters were produced (Guangzhi et al., 2017). Golin et al. postulated that during the electrospinning process, fibres take on moisture from the surrounding atmosphere; decrease in humidity leaves less water vapour present in the atmosphere, leading to less water absorption, hence fibres solidify more rapidly allowing less time for stretching (Golin, 2014). Our study included only two combinations of temperature and humidity variant, therefore, further experiment is needed to ascertain the effects of environmental factors on PET fibre diameter.

For the following experiments both $20 \%$ and $25 \%(w / v)$ PET membranes were investigated to determine difference between defect-containing and defect-free membranes.

\section{Mechanical testing and handling}

$20 \%$ PET membranes collected at the tip-to-collector distance of $30 \mathrm{~cm}$ exhibited lowest tensile strength (Figure 5.i.). There were no significant differences among other membranes. However, existing literature on poly( $\varepsilon$-caprolactone) materials demonstrated a positive correlation between collector distance and tensile strength (Asvar et al., 2017); increasing distance results in longer travel time to the collector, therefore the solution is able to undergo extended whipping, theoretically resulting in thinner and greater number of fibres per area. This results in fibres being more tightly packed leading to increased mechanical strength. This contradiction indicates that effects of electrospinning parameters on an output might be dependent on the polymer composition. Qualitative analysis of membranes during tensile testing showed both $20 \%$ and $25 \%(\mathrm{w} / \mathrm{v})$ membranes formed at tip-to-collector distance of $25 \mathrm{~cm}$ stretched most uniformly and did not reach point of failure after 10 minutes (Figure 5.ii.). Therefore, membranes spun with polymer concentration of 20 and $25 \%$ and collected at tip-to-collector distance of $25 \mathrm{~cm}$ were taken forward for further characterisation.

Both 20 and $25 \%(w / v)$ PET membranes could withstand folding, rolling and twisting equally well without being damaged (Figure 5.iii).

\section{Thickness and porosity}

$25 \%(\mathrm{w} / \mathrm{v})$ electrospun membranes were thicker and more porous than $20 \%(\mathrm{w} / \mathrm{v})$ membranes (TABLE 4). Higher polymer concentration led to thicker membrane due to production of thicker fibre and looser packing, resulting in larger voids between the fibres. High membrane porosity could also be explained by the same theory. 


\section{Wettability}

Untreated electrospun PET membranes exhibited poorer wettability versus untreated planar PET and tissue culture plastic (TCP) (ANOVA: $F=86.9, d f=14, p<0.0001$ ), in both defect-free $(25 \%(\mathrm{w} / \mathrm{v}))$ and defect-containing $(20 \%(\mathrm{w} / \mathrm{v}))$ membranes (Figure 6). Planar PET surfaces represent the inherent surface chemistry of PET as it had not been influenced by the electrospinning process. WCA of untreated planar PET was similar to that of TCP; the positive control widely used for cell culture. Our findings suggested that innate surface chemistry of PET was indeed hydrophilic, which could be attributed to oxygen molecules present in the PET polymer. Therefore, poor wettability was due to surface topography. Electrospun membranes are an open network of voids that exhibit rough surfaces leading to formation of air pockets between the drop and the membrane, a phenomenon referred to as Cassie-Baxter wetting state (SUSANNA LAURÉN). However, the inherent hydrophilic chemistry of the polymer would remain, and given the high surface area due to the membrane's morphology would expose more of the chemical structure on a molecular level. Biomaterial wettability has implications in cell attachment and interaction towards the surface of any given material. Webb et al. reported that cell attachment was significantly greater on hydrophilic surfaces relative to hydrophobic surfaces (Webb et al., 2000). Electrospun membranes can be modified to become more hydrophilic using treatments including, but not limited to, UV/ozone, weak acid, weak alkali and protein attachment e.g. bovine serum albumin.

We undertook further surface modification tests on defect-free membranes only $(25 \%$ $(w / v)$ ) to ensure that the only variables were: surface treatment type (UV, acid, alkali, or FCS) and treatment time (15 minutes and 30 minutes).

\section{Wettability \& ATR-FTIR after surface treatments}

Significant improvement in hydrophilicity was observed in membranes treated with $\mathrm{NaOH}$ $0.1 \mathrm{M} 30$ minutes, $1 \mathrm{M} \mathrm{NaOH}$ and diluted FCS irrespective of treatment times (Figure 7). Lowest WCA $\left(0^{\circ} \pm 0^{\circ}\right)$ was denoted for membranes submerged in $\mathrm{NaOH} 1 \mathrm{M} 30$ minutes, as the water drop did not persist long enough on the treated surface to measure. Contact angle of $\mathrm{NaOH}$-treated samples, decreased with increased concentration and submersion time. Mean WCA of membranes treated with diluted FCS also reduced with increased treatment time. No significant change was observed with increased FCS concentration, nor with UV or $\mathrm{HCl}$ treated membranes.

Hydrophilicity is influenced by three main factors (Haneef and Downes 2015, Polini and Yang 2017). Firstly, membrane surface chemistry governs the interactive forces between polar functional groups in the polymer surface with the polar water molecules. Secondly, fibre topography and structural architecture effects air trapping between the membrane pores, which can alter the interface between droplet and membrane surface. Lastly, the size of the water droplet can affect hydrogen bonding and the degree of droplet spread. As the droplet size was kept constant at $5 \mu \mathrm{l}$, this factor will not be discussed. Multiple groups regard WCA values less than $90^{\circ}$ to be hydrophilic (Purkait, Sinha et al. 2018), therefore all untreated PET membranes were hydrophobic $\left(130^{\circ} \pm 6.17\right)$. Theoretically, the presence of ester groups in the polymer backbone should promote hydrophilicity but this may have been counteracted by the non-polar phenyl cyclic hydrocarbon ring and hydrocarbon backbone that repels the 
polar water molecule. In addition, surface roughness as a result of electrospun topography and random fibre orientation promotes air trapping between membrane voids, increasing WCA.

Figure 7 illustrated improvement of hydrophilicity in membranes treated with $\mathrm{NaOH}$ to be a concentration- and submersion-time-dependent process. Treating membranes with $\mathrm{NaOH} 1$ M 30 minutes turned it into a superwetting material. $\mathrm{NaOH}$ solution performs random chemical scission on ester linkages, resulting in exposure of hydroxyl and carboxylate groups on the polymer surface. These functional groups are able to form hydrogen bonds with water molecules, and in turn improve hydrophilicity. ATR-FTIR exhibited the change in surface functional groups following treatment with $\mathrm{NaOH}$ and $\mathrm{HCl}$; untreated membranes showed strong ester bonds as expected and was correctly identified as PET (Figure 8a). Both wet chemical treatments (Figure $\mathbf{8 b}-\mathbf{c}$ ) exhibited a stronger hydroxyl group peak than the untreated membrane due to hydrogen bonds in the carboxylate group and secondary alcohols. Both spectra also showed more $\mathrm{C}-\mathrm{H}$ stretching as a result of chemical scission.

The infrared spectra of $\mathrm{NaOH}$-treated membrane (Figure 8b) correlated with reduction in WCA as it showed the presence of hydrophilic hydroxyl group. This is shown by an increased intensity of bands in the $3200-3550 \mathrm{~cm}^{-1}$ region and the $2960 \mathrm{~cm}^{-1}$ peak compared to the untreated membrane. Although exhibiting similar spectra, $\mathrm{HCl}$-treated membranes did not demonstrate significant reduction in WCA, which correlated with a much lower detection intensity in the aforementioned peaks (Figure 8c). This may be because hydrolysis of esters catalysed by acid is much slower at any given temperature than alkali-catalysed hydrolysis (Mashiur 2012). It may be that the small alteration in surface chemistry that was detected by ATR-FTIR for $\mathrm{HCl}$ treated membranes was not significant enough to translate to a change in physical properties.

Submerging membranes in diluted FCS solution promotes protein adsorption. The protein attaches via interactions such as weak Van der Waal forces, electrostatic forces, hydrogen bonds and hydrophobic dehydration (Tallawi M 2015). Hydrophobic dehydration happens between hydrophobic regions on the surface and hydrophobic domains on the protein structure. This interaction promotes protein conformational change and unfolding. Regardless of protein original structural arrangement, such unfolding increases the exposure of active sites for protein surface contacts (Felgueiras, Antunes et al. 2018). Membranes treated with neat FCS had higher WCA than the diluted FCS group and had no significant change compared to the untreated group. Protein adsorption is complex and depends on many factors. Firstly, many proteins exist in FCS and the Stokes-Einstein-Sutherland equation predicted that small proteins will diffuse faster than larger proteins. Secondly, solution concentration influences the extent of protein saturation on the material surface. If the surface is sub-saturated, then there is available space for proteins to unfold and favourable conformation may be achieved, whereas proteins on saturated surfaces must displace adsorbed neighbours, slowing down the unfolding process. At surface saturation (which may be the case in the neat FCS group), smaller proteins that arrived quickly has already formed a monolayer coverage. Larger proteins that reach the membrane subsequently, then forms multi-layer absorption on top of the smaller proteins. However, this form of adsorption is weaker and larger proteins can be washed off during the rinse with deionised water immediately after treatment. Therefore, membranes treated with 
neat FCS may have less attachment of larger proteins compared to membranes submerged in diluted FCS. As larger proteins contain more functional groups and can contribute to membrane hydrophilicity more significantly than smaller proteins, the reduction in WCA is therefore limited in the neat FCS group (Vogler 2011, Felgueiras, Antunes et al. 2018). ATRFTIR for FCS treated membranes exhibited no change in surface chemistry (data not shown).

There was no significant reduction of WCA of membranes after UV irradiation. This is conflicting with existing evidence that shows drastic improvement in hydrophilicity (from $83.8^{\circ} \pm 1.0$ to $40.8^{\circ} \pm 1.4$ ) in PET films after treatment with UV excimer light at $15.8 \mathrm{~mJ} \mathrm{~cm}$ for 2 - 90 seconds (Gotoh, Yasukawa et al. 2011). Reduction in WCA was attributed to the introduction of oxygen-containing groups onto the film surface after UV treatment, leading to an increase in the base parameter of the surface free energy. UV treatment also results in the formation of low-molecular-weight oxidised materials (LMWOM) on the polymer surface, arising from random scission of polymer chain to form hydrophilic oligomers (Gotoh, Yasukawa et al. 2011). However, these hydrophilic groups can undergo surface rearrangement and be lost to the atmosphere over time in a process called 'hydrophobic recovery', hence losing its hydrophilicity. In this work, WCA was measured 1-week posttreatment. This coincides with the time-point whereby hydrophobic recovery reaches stability in the literature, which may explain the lack of WCA reduction post UV irradiation. Gotoh et al. suggested rinsing the membrane with water immediately after treatment may help suppress the extent of hydrophobic recovery. ATR-FTIR for UV treated membranes exhibited no change in surface chemistry (data not shown).

Although there is evidence that hydrophilic scaffolds can improve cell adhesion, extreme hydrophilicity may not be desirable. Cell adhesion studies carried out using human osteosarcoma cell on polystyrene scaffold concluded that optimal adhesion was observed at WCA of $64^{\circ}$ (Dowling, Miller et al. 2011). This correlates with a study on low density polyethylene surface, which demonstrated stronger adhesion force at WCA approximately $60-65^{\circ}$ (Xu and Siedlecki 2007). Membranes with mean WCA closest to this range are those treated with $\mathrm{NaOH} 1 \mathrm{M} 15$ minutes $\left(75.1^{\circ} \pm 37.4\right)$ and diluted FCS 15 minutes $\left(75.6^{\circ} \pm 33.0\right)$.

\section{Fibre morphology and diameter after surface treatments}

Figure 9 shows representative SEM images of fibre morphology in each treatment group and the corresponding histogram plot of fibre diameters. All surface treatments resulted in morphological change to varying degrees, except for FCS (data not shown). $1 \mathrm{M} \mathrm{NaOH}-$ treated membranes appears to have the roughest morphology and those treated with $\mathrm{HCl}$ underwent the least change. Rough morphology in most treatment groups was limited to the surface, however fibres treated with $1 \mathrm{M} \mathrm{NaOH}$, irrespective of submersion time, showed deeper degradation and salt crystal deposition. $\mathrm{NaOH}$ attacked a large proportion of the fibre surface, causing significant surface etching and extends inside the fibre, leading to formation of elongated cavities on the surface (Figure 9(g)).

There is evidence that cell adhesion and cell proliferation is improved on rough surfaces and thinner fibres (Anselme 2000, Xu, Yang et al. 2004, Wan, Wang et al. 2005) (Kurokawa, Endo et al. 2017), however treatment parameters must be balanced to minimise compromise to mechanical integrity. Furthermore, existing literature reported that rougher surfaces give 
higher WCA (Cui, Li et al. 2008). However, this contradicts with the results from our study as $\mathrm{NaOH}$-treated membranes resulted in lowest WCA values. Membranes treated with $\mathrm{NaOH} 1$ M 15 minutes and those treated with $\mathrm{HCl} 0.1 \mathrm{M} 30$ minutes both resulted in significant reduction in mean diameter compared to untreated membranes; $30.6 \%$ and $22.1 \%$ decrease, respectively. Previous work has shown that $\mathrm{NaOH}$ can lead to fibre thinning (Musale and Shukla 2016) and membrane weight reduction (Lee, Park et al. 2012) but there is lack of such evidence for $\mathrm{HCl}$.

\section{Mechanical properties after surface treatments}

The scatter plot shown in Figure 10.i. is a representative plot illustrating the relationship between force and displacement during 10 cycles of stretch and relaxation of membranes. There is no statistical difference between each cycle $(p=0.966)$ which means that the membrane did not lose its elastic property during repeated cyclic tensile test. This is true for membranes in every treatment group. It can be seen that the 'stretch' phase of the first cycle required more force to achieve the same displacement as subsequent cycles. The graph for most samples followed this trend, except membranes treated with $0.1 \mathrm{M} \mathrm{HCl}$ where there was no observable distinction between the initial cycle and the subsequent cycles.

On a molecular level, during the relaxed state the polymer chains are coiled and when stretched the chains are extended, acting like springs. As long as the uniaxial load applied is not sufficient to break the chemical bonds, the membrane will return to its original form. Although not statistically significant, the initial stretch phase can be seen to follow a different trend compared to subsequent cycles and require higher force to achieve the same displacement. This initial force might have been used to break interactions between polymer chains that kept the chains 'coiled', but insufficient to disrupt intermolecular bonds that will render the membrane plastic. Further, the stretch phase of the first cycle follows the Maxwell model of viscoelasticity (Schiavi and Prato 2016); when the material is subjected to constant strain, the stresses gradually relax. This is shown by the shape of the graph whereby the force tapers off as it reaches maximum displacement. Meanwhile, the graph of subsequent cycles follows a near-perfect linear relationship ( $R^{2}$ of the 'stretch' phase of cycles 2 to 10 in Figure 10 i) is $0.999 \pm 0.00025$ ).

Following repeated cyclic tensile test, the membranes were subjected to 10 minutes of continuous stretching at the rate of $3 \mathrm{~mm}$ per minute or until failure, whichever was achieved first. Young's modulus was calculated and can be described as the ability of the material to store potential energy and release it upon deformation (Schiavi and Prato 2016). The higher the modulus, the stiffer it is. $\mathrm{NaOH} 1 \mathrm{M} 15$ minutes treatment group exhibited significantly higher modulus than untreated membranes (Figure 10.ii.). These membranes were also the fastest to fracture during the tensile test. These two findings suggest that this treatment makes the membrane more brittle.

\section{Permeability assay}

Permeability assay was performed as an indirect measure of total membrane permeability. Figure 11 shows the concentration of FITC that permeated through the membrane at 
different time-points, expressed as a percentage of the original FITC concentration that was pipetted into the transwell insert $(0.0185 \mathrm{mmol})$. Membranes treated with $\mathrm{NaOH} 1 \mathrm{M} 30$ minutes exhibited higher permeability than untreated membranes. This correlates with WCA results as improved hydrophilicity implies more spreading of water droplet across the membrane, thereby increasing the contact area of FITC to the membrane at any given time, facilitating permeation. The percentage of permeated FITC did not increase with time, suggesting that concentration of FITC had equilibrated across the membrane after 10 minutes of permeation.

\section{Overview Discussion}

The challenges of developing bioengineered intestinal constructs are complex; not only because of the multiple cell types and layers that interact within the native small intestine, but because the construct must also conform to adequate vascularisation (cultured or engineered) to enable absorption and secretion, as well as withstand/undergo peristaltic action to move digested bulk through the construct, all while maintaining its structure. To tackle this will require a joint-venture between multiple research groups of bioengineers, materials scientists, cell biologists, and clinicians (Clever et al 2019).

Our material has potential to be used in small bowel bioengineering applications; including 3D models or as a potential for TESI. We anticipate further manipulating the material to conform to the tubular structure of the native small bowel to take forward for 3D in vitro cell or organoid culture. Patient et al. have developed a proposed 3D intestinal in vitro model that showed collagen I treated electrospun PET improved Caco-2 cell monolayer formation which exhibited transepithelial electrical resistance properties similar to ex vivo porcine tissue (Patient et al. 2019). Interest has been raised in developing a wholly engineered approach to developing a functional, off-the-shelf product in application for small bowel transplants (Clevers et al. 2019). Our contribution adds to this area of research by presenting a biomaterial that has been reported to be suitable for intestinal cell culture (Patient et al 2019) which can undergo cycles of mechanical stress after exposure to acids, alkali and proteins and is capable of maintaining its structural and physical integrity.

\section{Conclusion}

Our study investigated the use of electrospun PET as a potential biomaterial for small intestine bioengineering applications. We characterised the effects of polymer concentration, collecting distance, voltage, flow rate, collecting time, temperature, humidity, and surface treatment on electrospun PET scaffolds. Polymer concentration played the most significant role in determining fibre morphology and diameter. PET fibres were produced at nano-scaled diameters and formed robust membranes with good mechanical properties. Although electrospun membranes were relatively hydrophobic, the surface chemistry of PET was hydrophilic. Treating membranes with $1 \mathrm{M} \mathrm{NaOH}$ for 15 minutes yielded significant improvements in WCA, fibre thinning, rougher membrane topography and enhancement of hydroxyl groups to the polymer surface, with no 
bioRxiv preprint doi: https://doi.org/10.1101/2021.10.23.465560; this version posted October 25, 2021. The copyright holder for this preprint (which was not certified by peer review) is the author/funder, who has granted bioRxiv a license to display the preprint in perpetuity. It is made available under aCC-BY-NC-ND 4.0 International license.

compromise to the mechanical integrity and membrane elasticity. The material fabricated was porous and permeability properties were improved post-treatment. Electrospinning could, therefore, be used as a potentially cost-effective alternative to fabricate a biomaterial for small bowel engineering applications. 


\section{Figure Legends}

Figure 1. Schematic representation of the polymerisation reaction to form PET. Drawn using ChemWriter.

Figure 2. Schematic diagram of electrospinning setup. Drawn using BioRender.

Figure 3. (i) Schematic diagram of dogbone sample dimensions (ii) Labelled stress vs strain curve showing elastic and plastic region

Figure 4. (i) SEM micrographs show polymer solution concentration affected fibre morphology. (A) 25\% (w/v) PET/HFIP, (B) 20\% (w/v) PET/HFIP, (C) $15 \%$ (w/v) PET/HFIP, (D) $10 \%(\mathrm{w} / \mathrm{v})$ PET/HFIP; all fibres spun at tip-to-collector distance of $25 \mathrm{~cm}$. Large image magnification: 5000x, small image magnification: 10 000x. Scale bar $20 \mu \mathrm{m}$. (ii) Scatter plot show polymer concentration had positive relationship with fibre diameter. All data presented as mean and $\mathrm{Cl}$. (iii) Frequency distribution graph of electrospun PET fibre diameter at different polymer concentrations. All data presented as mean \pm SD. @ vs. all groups, $* * * *=p<0.0001 . n=750$ for concentrations of $25 \%, 20 \%$ and $15 \%, n=700$ for concentration of $10 \%$ (iv) SEM micrographs showing that temperature and humidity did not affect fibre morphology. (A) Low temperature and high humidity, (B) High temperature and low humidity. Magnification: 5000x. Scale bar $20 \mu \mathrm{m}$.

Figure 5. (i) Violin plot show $20 \%(w / v)$ membranes collected at $30 \mathrm{~cm}$ had the lowest tensile strength. Violin plot indicates upper and lower quartiles and middle dotted line represents the median. ANOVA: $F=2.634, d f=29, p$-value< 0.05 . Tukey post hoc: $\$$ vs. $25 \%$ at $30 \mathrm{~cm}$, @ vs. $25 \%$ at $25 \mathrm{~cm} .{ }^{*}=p<0.05, * *=0.001 \leq p \leq 0.01$ (ii) Photographs show intact PET membranes stretched uniformly after tensile testing. (A) $25 \%(\mathrm{w} / \mathrm{v})$ collected at $25 \mathrm{~cm}$, (B) $20 \%(\mathrm{w} / \mathrm{v}$ ) collected at $25 \mathrm{~cm}$ (iii) Photographs of PET membranes undergoing (A),(D) folding, (B),(E) rolling and (C),(F) twisting without being damaged. (A)-(C) are 20\% PET/HFIP fibres, (D)-(F) are 25\% PET/HFIP fibres

Figure 6. PET membranes were more hydrophobic than planar surfaces and tissue culture plastic. Images comparing WCA between positive control, planar surfaces and fibres made from $20 \%$ and $25 \%(\mathrm{w} / \mathrm{v}$ ) PET/ HFIP concentrations. (A) WCA on treated polystyrene, (B) WCA on planar surface (C) WCA on membrane surface. Violin plot indicates upper and lower quartiles and middle dotted line represents the median. \& vs. 20\% fibre, \$ vs. $25 \%$ fibre, @ vs. $20 \%$ planar. $*=p<0.05, * * * *=p<0.0001$

Figure 7. Membranes treated with $0.1 \mathrm{M} \mathrm{NaOH}$ for 30 minutes, $1 \mathrm{M} \mathrm{NaOH}$ and diluted FCS show significant reduction in WCA. WCA measurement of treated membranes to determine degree of hydrophilicity. Lowest WCA observed in $1 \mathrm{M} \mathrm{NaOH}$ for 30 minutes treatment group. Data are shown as mean \pm standard deviation, $n=9$. Two-way ANOVA: $F_{(13,104)}=29.6$, $\mathrm{df}=13, \mathrm{p}$-value $<0.05$. Dunnett's multiple comparisons test: ** $\mathrm{p}=0.005, * * * * \mathrm{p}<0.0001$. Surface treatments written as 'Treatment_Submersion time'.

Figure 8. Membranes treated with $\mathrm{HCl}$ and $\mathrm{NaOH}$ showed more intense $-\mathrm{OH}$ bands and $\mathrm{C}-$ $H$ stretching than untreated membranes. ATR-FTIR spectra was used to analyse the surface 
chemistry of PET membrane. (a-c) are representative spectra of membranes treated with wet chemical method: (a) untreated, (b) treated with $\mathrm{HCl}$ and (c) treated with $\mathrm{NaOH}$.

Figure 9. Every surface treatment condition led to fibre morphological change. Membranes treated with $1 \mathrm{M} \mathrm{NaOH}$ for 15 minutes and membranes treated with $0.1 \mathrm{M}$ $\mathrm{HCl}$ for 30 minutes both had reduced fibre diameters. Representative SEM images demonstrating the effects of different surface treatments on membrane morphology (magnification $\times 15,000$, except $(f) \times 10,000$ ) and histogram plot of fibre diameter frequency distribution $(n=150)$.

(a) untreated, (b) UV for 15 minutes, (c) UV for 30 minutes, (d) $0.1 \mathrm{M} \mathrm{NaOH}$ for 15 minutes, (e) $0.1 \mathrm{M} \mathrm{NaOH}$ for 30 minutes, (f) $1 \mathrm{M} \mathrm{NaOH}$ for 15 minutes, (g) $1 \mathrm{M} \mathrm{NaOH}$ for 30 minutes, (h) $0.1 \mathrm{M} \mathrm{HCl}$ for 15 minutes, (i) $0.1 \mathrm{M} \mathrm{HCl}$ for 30 minutes and (j) $1 \mathrm{M} \mathrm{HCl}$ for 30 minutes. Kruskal-Wallis: $p<0.0001$. Dunnett's multiple comparison: $* * * *=p<0.0001$

Figure 10. Membranes in every treatment group were able to retain its elastic property during repeated cyclic tensile test. (i) Membranes were subjected to 10 stretch-relaxation cycles during tensile testing to evaluate its elasticity. Representative force vs displacement scatter plot demonstrates similar trend across all cycles. Gradient of the stretch phase of each cycle was subjected to statistical analysis. One-way ANOVA: $F_{(9,20)}=0.300, d f=9$, $p$ value $=0.966$. (ii) $\mathrm{NaOH} 1 \mathrm{M} 15$ minutes treatment group exhibited significantly higher modulus than untreated membranes.

Figure 11. Membranes treated with $1 \mathrm{M} \mathrm{NaOH}$ for 30 minutes was more permeable than untreated membrane at the 10 - and 60 -minute time-point during the assay. Permeability assay was performed on the untreated group and $\mathrm{NaOH} 1 \mathrm{M} 30$ minutes group as an indirect measure of total membrane permeability. FITC was used for fluorescence detection. Data are shown as mean \pm standard deviation where applicable. Two-way ANOVA: $F_{(1,8)}=50.6$, $d f$ $=1, p$-value $=0.0001$. Dunnett's multiple comparison: $* * p=0.0014, * * * p=0.0009$ 
Table 1: Summary of the range of PET/HFIP concentration and tip-to-collector distance used Tables

\begin{tabular}{|c|c|c|c|c|}
\hline Parameter & \multicolumn{4}{|c|}{ Range } \\
\hline $\begin{array}{c}\text { Concentration of } \\
\text { PET/HFIP (\%) }\end{array}$ & 25 & 20 & 15 & 10 \\
\hline $\begin{array}{c}\text { Tip-to-collector } \\
\text { distance }\end{array}$ & $30,25,20,15$, & $30,25,20,15$, & $30,25,20,15$, & $30,25,20,15$, \\
\hline
\end{tabular}

Table 2: Summary of the range of operation parameters and environmental factors All membranes were electrospun at voltage: $25 \mathrm{kV}$, flow rate: $2 \mathrm{ml} / \mathrm{hr}$, collection time: 15 minutes, humidity and temperature at standard lab conditions

\begin{tabular}{|c|c|}
\hline Parameter & Range \\
\hline Voltage (kV) & $15,20,25,30,35$ \\
\hline Solution flow rate (ml/hr) & $1,2,2.5,3$ \\
\hline Collection time (minutes) & $15,30,45,60$ \\
\hline Humidity (\%) & Low (19), High (40) \\
\hline Temperature ( $^{\circ}$ ) & Low (20.5), High (30.3)
\end{tabular}

Table 3: There were no significant correlation between average fibre diameter in each parameter. All data presented as mean \pm SD.

\begin{tabular}{|c|c|c|c|c|c|}
\hline Operatlon parameter & Range & & & & \\
\hline Voltage (kV) & 35 & 30 & 25 & 20 & 15 \\
\hline Flbre diameter $(\mu \mathrm{m})$ & $0.947 \pm 0.347$ & $1.32 \pm 0.363$ & $1.31 \pm 0.501$ & $0.884 \pm 0.513$ & $1.3 \div \pm 0.498$ \\
\hline Flow rate $(\mathrm{ml} / \mathrm{hr})$ & 3 & 2.5 & 2 & 1 & \\
\hline Flbre dlameter ( $\mu \mathrm{m})$ & $1.27 \pm 0.471$ & $1.35 \pm 0.336$ & $1.31 \pm 0.501$ & $1.12 \pm 0.319$ & \\
\hline Collection time (mins) & 60 & 45 & 30 & 15 & \\
\hline Filbre diameter ( $\mu \mathrm{m})$ & $1.22 \pm 0.376$ & $1.24 \pm 0.343$ & $1.33 \pm 0.412$ & $1.31 \pm 0.501$ & \\
\hline
\end{tabular}

Table 4: $\mathbf{2 5 \%}(\mathrm{w} / \mathrm{v})$ membranes are thicker and more porous than $\mathbf{2 0 \%}(\mathrm{w} / \mathrm{v})$ membranes. Both electrospun at tip-to-collector distance of $25 \mathrm{~cm}$. All data presented as mean \pm SD.

\begin{tabular}{|c|c|c|}
\hline Fibre parameters & Thickness $(\mu \mathrm{m})$ & Porosity $(\%)$ \\
\hline $20 \%$ PET/HFIP at $25 \mathrm{~cm}$ & $50.0 \pm 8.16$ & $89.3 \pm 2.9$ \\
\hline $25 \%$ PET/HFIP at $25 \mathrm{~cm}$ & $76.7 \pm 9.43$ & $92.6 \pm 1.9$ \\
\hline
\end{tabular}




\section{Conflict of interest}

None

\section{Author Contributions}

KK carried out the data collection and analyses, wrote the entire manuscript and made the figures and tables. AH led the research, contributed to writing the manuscript, reviewed and edited the manuscript.

\section{Acknowledgements}

The authors would like to acknowledge Alison Beckett (University of Liverpool) for her help with the SEM to image the fibrous membrane and Dr Keith Arnold (Materials Innovations Factory, Liverpool) for his help with SEM in imaging the membranes after surface treatments.

\section{References}

AGRAHARI, V., AGRAHARI, V., MENG, J. \& MITRA, A. K. 2017. Chapter 9 - Electrospun Nanofibers in Drug Delivery: Fabrication, Advances, and Biomedical Applications. In: MITRA, A. K., CHOLKAR, K. \& MANDAL, A. (eds.) Emerging Nanotechnologies for Diagnostics, Drug Delivery and Medical Devices. Boston: Elsevier.

Anselme, K. (2000). "Osteoblast adhesion on biomaterials." Biomaterials 21(7): 667-681.

ASVAR, Z., MIRZAEI, E., AZARPIRA, N., GERAMIZADEH, B. \& FADAIE, M. 2017. Evaluation of electrospinning parameters on the tensile strength and suture retention strength of polycaprolactone nanofibrous scaffolds through surface response methodology. Journal of the Mechanical Behavior of Biomedical Materials, 75, 369-378.

BHARADWAJ, S., TANDON, P., MEKA, K., RIVAS, J. M., JEVENN, A., KUO, N.-T. \& STEIGER, E. 2016. Intestinal Failure: Adaptation, Rehabilitation, and Transplantation. Journal of Clinical Gastroenterology, 50.

BUCHKO, C. J., CHEN, L. C., SHEN, Y. \& MARTIN, D. C. 1999. Processing and microstructural characterization of porous biocompatible protein polymer thin films. Polymer, 40, 73977407.

CLARK, J. 2004. POLYESTERS [Online]. Chemguide. Available: https://www.chemguide.co.uk/organicprops/esters/polyesters.html [Accessed 09/01/2020 2020].

Clevers et al (2019) Tissue-Engineering the Intestine: The Trials before the Trials. Cell Stem Cell

Cui, W., et al. (2008). "Degradation patterns and surface wettability of electrospun fibrous mats." Polymer Degradation and Stability 93(3): 731-738. 
CUSTOM-PAK. 2018. What Plastics Are Approved for Food Contact Applications? [Online]. Custon-Pak. Available: https://www.custom-pak.com/what-plastics-are-approved-for-foodcontact-applications/ [Accessed 08/01/2020 2020].

DE SCHOENMAKER, B., VAN DER SCHUEREN, L., CEYLAN, Ö. \& CLERCK, K. 2012. Electrospun Polyamide 4.6 Nanofibrous Nonwovens: Parameter Study and Characterization. Journal of Nanomaterials, 2012.

Dowling, D., et al. (2011). "Effect of Surface Wettability and Topography on the Adhesion of Osteosarcoma Cells on Plasma-modified Polystyrene." Journal of biomaterials applications 26: 327-347.

Felgueiras, H. P., et al. (2018). 1 - Fundamentals of protein and cell interactions in biomaterials. Peptides and Proteins as Biomaterials for Tissue Regeneration and Repair. M. A. Barbosa and M. C. L. Martins, Woodhead Publishing: 1-27.

FONG, H., CHUN, I. \& RENEKER, D. H. 1999. Beaded nanofibers formed during electrospinning. Polymer, 40, 4585-4592.

GOLIN, A. P. 2014. Humidity Effect on the Structure of Electrospun Core-Shell PCL-PEG Fibers for Tissue Regeneration Applications. Master of Engineering Science, The University of Western Ontario.

Gotoh, K., et al. (2011). "Wettability characteristics of PET films treated by atmospheric pressure plasma and ultraviolet excimer light." Polymer Journal 43.

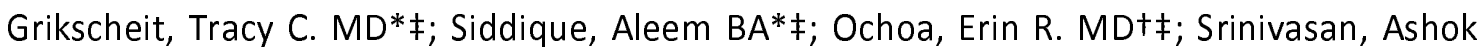
PhD§; Alsberg, Eben PhDll; Hodin, Richard A. MD*;; Vacanti, Joseph P. MD*‡ TissueEngineered Small Intestine Improves Recovery After Massive Small Bowel Resection, Annals of Surgery: November 2004 - Volume 240 - Issue 5 - p 748-754 doi: 10.1097/01.sla.0000143246.07277.73

GUANGZHI, Y., LI, H., YANG, J.-H., WAN, J. \& YU, D. 2017. Influence of Working Temperature on The Formation of Electrospun Polymer Nanofibers. Nanoscale Research Letters, 12.

hAEFNER, S., BENZAQUEN, M., BÄUMCHEN, O., SALEZ, T., PETERS, R., MCGRAW, J. D., JACOBS, K., RAPHAËL, E. \& DALNOKI-VERESS, K. 2015. Influence of slip on the PlateauRayleigh instability on a fibre. Nature Communications, 6, 7409.

HANEEF, A. S. \& DOWNES, S. 2015. Assessing the Suitability of Electrospun Poly(Ethylene Terephthalate) and Polystyrene as Cell Carrier Substrates for Potential Subsequent Implantation as a Synthetic Bruch's Membrane. International Journal of Polymeric Materials and Polymeric Biomaterials, 64, 320-332.

HEKMATI, A., RASHIDI, A., GHAZISAEIDI, R. \& DREAN, J.-Y. 2013. Effect of needle length, electrospinning distance, and solution concentration on morphological properties of polyamide-6 electrospun nanowebs. Textile Research Journal, 83, 1452-1466. 
HTIKE, H. H., LONG, C. \& SUKIGARA, S. 2012. The Effect of Relative Humidity on Electrospinning ofPoly-(vinyl alcohol) with Soluble Eggshell Membrane. Journal of Textile Engineering, 58, 9-12.

JUN, I., HAN, H. S., EDWARDS, J. R. \& JEON, H. 2018. Electrospun Fibrous Scaffolds for Tissue Engineering: Viewpoints on Architecture and Fabrication. Int J Mol Sci, 19.

KAJDIČ, S., VREČER, F. \& KOCBEK, P. 2018. Preparation of poloxamer-based nanofibers for enhanced dissolution of carvedilol. European Journal of Pharmaceutical Sciences, 117, 331340.

KIM, G. T., LEE, J. S., SHIN, J. H., AHN, Y. C., JEONG, K. H., SUNG, C. M. \& LEE, J. K. 2004. Effect of Humidity on the Microstructures of Electrospun Polystyrene Nanofibers. Microscopy and Microanalysis, 10, 554-555.

Kurokawa, N., et al. (2017). Chapter 8 - Electrospinning and surface modification methods for functionalized cell scaffolds. Nanostructures for Novel Therapy. D. Ficai and A. M. Grumezescu, Elsevier: 201-225.

Lanza, R., et al. (2007). Principle of Tissue Engineering.

Lee, J. H., et al. (2012). "Effect of pretreatment conditions on the hydrolysis and water absorption behavior of poly(ethylene terephthalate) fibrous assembly." Polymer International 61(4): 657-663.

MAK, K. M. \& MEI, R. 2017. Basement Membrane Type IV Collagen and Laminin: An Overview of Their Biology and Value as Fibrosis Biomarkers of Liver Disease. The Anatomical Record, 300, 1371-1390.

Mashiur, R. (2012). Degradation of Polyesters in Medical Applications. Polyester. H. E.-D. M. Saleh, IntechOpen.

MAZOOCHI, T., AHMADI, S. M., HAMADNIAN, M. \& JABBARI, V. 2012. Investigation on the Morphological Characteristic of Nanofiberous Membrane as Electrospun in the Different Processing Parameters. International Journal of Industrial Chemistry, 3, 2-9.

Middleton SJ, Jamieson NV (2005) The current status of small bowel transplantation in the UK and internationally, Gut, 54:1650-1657

MILLERET, V., SIMONA, B., NEUENSCHWANDER, P. \& HALL, H. 2011. Tuning electrospinning parameters for production of 3D-fiber-fleeces with increased porosity for soft tissue engineering applications. Eur Cell Mater, 21, 286-303.

Musale, R. and S. Shukla (2016). "Weight reduction of polyester fabric using sodium hydroxide solutions with additives cetyltrimethylammonium bromide and [BMIM]Cl." The Journal of The Textile Institute 108: 1-7.

OGULATA, T. \& içOĞLU, H. 2013. Effect of Ambient Parameters on Morphology of Electrospun Polyetherimide (PEI) Fibers. Tekstil ve Konfeksiyon, 23, 313-318. 
Patient JD. et al(2019) Nanofibrous Scaffolds Support a 3D in vitro Permeability Model of the Human Intestinal Epithelium, Frontiers in Pharmacology

Polini, A. and F. Yang (2017). 5 - Physicochemical characterization of nanofiber composites. Nanofiber Composites for Biomedical Applications. M. Ramalingam and S. Ramakrishna, Woodhead Publishing: 97-115.

Purkait, M. K., et al. (2018). Chapter 4 - Photoresponsive Membranes. Interface Science and Technology. M. K. Purkait, M. K. Sinha, P. Mondal and R. Singh, Elsevier. 25: 115-144.

Schalamon, J., et al. (2004). "Mortality and economics in short bowel syndrome." Best practice \& research. Clinical gastroenterology 17: 931-942.

Schiavi, A. and A. Prato (2016). Non-linear stress relaxation of polymers: experimental evidences and stretched exponential model.

SUBRAMANIAM, A. \& SETHURAMAN, S. 2014. Chapter 18 - Biomedical Applications of Nondegradable Polymers. In: KUMBAR, S. G., LAURENCIN, C. T. \& DENG, M. (eds.) Natural and Synthetic Biomedical Polymers. Oxford: Elsevier

SUSANNA LAURÉN, P. Contact angle - What is it and how do you measure it? [Online]. Biolin Scientific.

Available: https://www.biolinscientific.com/hubfs/Content\%200ffer/Attension/EN/WP\%20Contact\%2 Oangle\%20What\%20is\%20it\%20and\%20how\%20do\%20you\%20measure\%20it.pdf?hsLang=e n [Accessed 11/01/2020 2020].

Tallawi M, R. E., Barbani N, Cascone M G, Rai R, Saint-Pierre G and Boccaccini A R (2015). "Strategies for the chemical and biological functionalization of scaffolds for cardiac tissue engineering: a review." J. R. Soc. Interface 12.

Tappenden, K. (2014). "Pathophysiology of Short Bowel Syndrome Considerations of Resected and Residual Anatomy." JPEN. Journal of parenteral and enteral nutrition 38.

VANCAMELBEKE, M. \& VERMEIRE, S. 2017. The intestinal barrier: a fundamental role in health and disease. Expert Rev Gastroenterol Hepatol, 11, 821-834.

Vass P., et al (2019) Scale-up of electrospinning technology: Applications in the pharmaceutical industry, Wires Nanomedicine and Nanobiotechnology

Vogler, E. (2011). "Protein Adsorption in Three Dimensions." Biomaterials 33: 1201-1237.

Wan, Y., et al. (2005). "Adhesion and proliferation of OCT-1 osteoblast-like cells on microand nano-scale topography structured poly(l-lactide)." Biomaterials 26(21): 4453-4459.

WANG, C., CHIEN, H.-S., HSU, C.-H., WANG, Y.-C., WANG, C.-T. \& LU, H.-A. 2007. Electrospinning of Polyacrylonitrile Solutions at Elevated Temperatures. Macromolecules, 40.

WEBB, K., HLADY, V. \& TRESCO, P. A. 2000. Relationships among cell attachment, spreading, cytoskeletal organization, and migration rate for anchorage-dependent cells on model surfaces. J Biomed Mater Res, 49, 362-8. 
Xu, C., et al. (2004). "In vitro study of human vascular endothelial cell function on materials with various surface roughness." Journal of Biomedical Materials Research Part A $71 A(1)$ : 154-161

Xu, L.-C. and C. A. Siedlecki (2007). "Effects of surface wettability and contact time on protein adhesion to biomaterial surfaces." Biomaterials 28(22): 3273-3283.

XUE, J., XIE, J., LIU, W. \& XIA, Y. 2017. Electrospun Nanofibers: New Concepts, Materials, and Applications. Accounts of Chemical Research, 50, 1976-1987.

Yeste, J., Illa, X., Alvarez, M. et al. Engineering and monitoring cellular barrier models. J Biol Eng 12, 18 (2018). https://doi.org/10.1186/s13036-018-0108-5

YU, J. H., FRIDRIKH, S. V. \& RUTLEDGE, G. C. 2006. The role of elasticity in the formation of electrospun fibers. Polymer, 47, 4789-4797.

ZARGHAM, S., BAZGIR, S., TAVAKOLI, A., RASHIDI, A. \& DAMERCHELY, R. 2012. The Effect of Flow Rate on Morphology and Deposition Area of Electrospun Nylon 6 Nanofiber. Journal of Engineered Fibers and Fabrics, 7, 42-49.

ZHAO, S., WU, X., WANG, L. \& HUANG, Y. 2004. Electrospinning of ethyl-cyanoethyl cellulose/tetrahydrofuran solutions. Journal of Applied Polymer Science, 91, 242-246. 

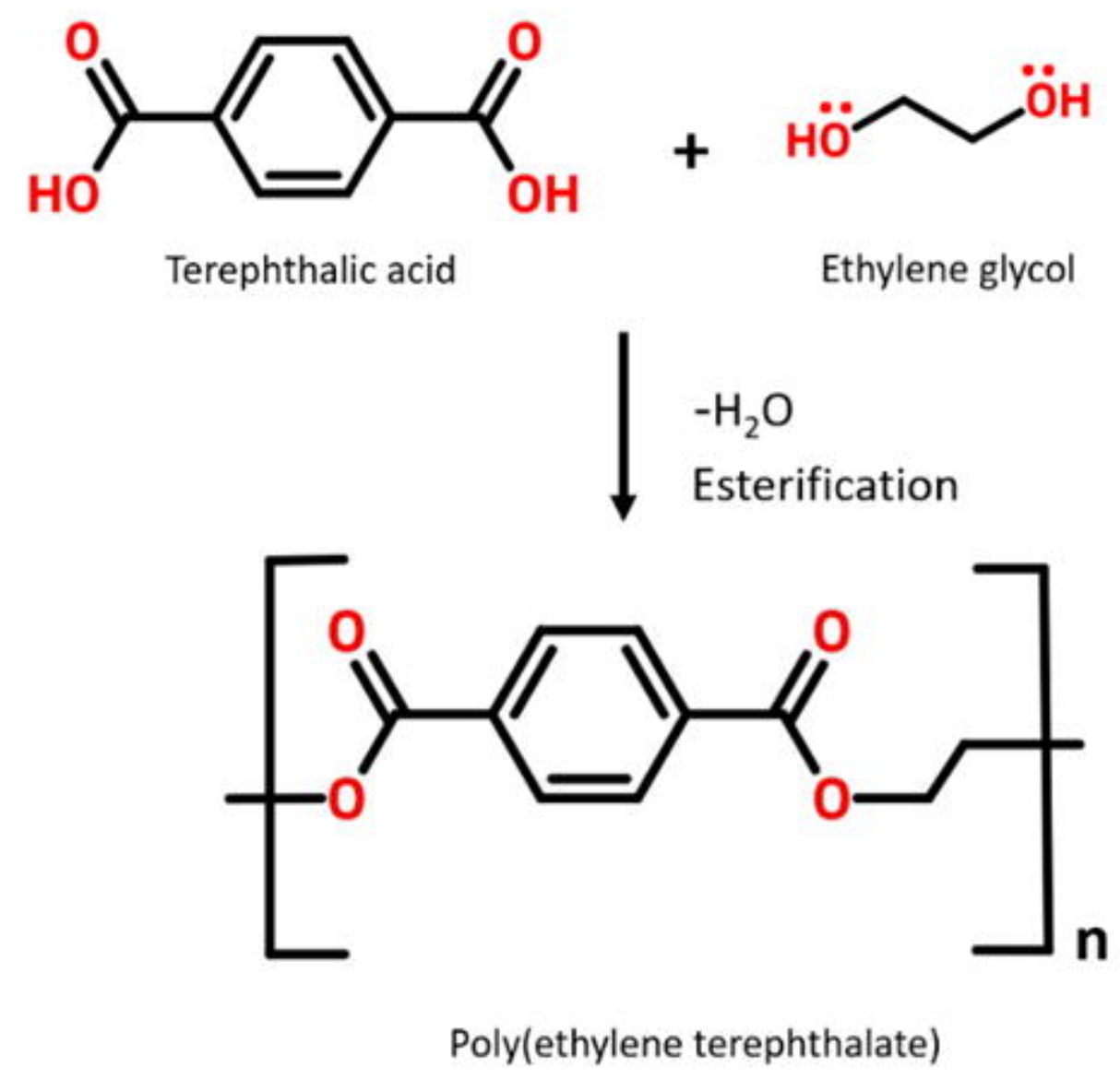


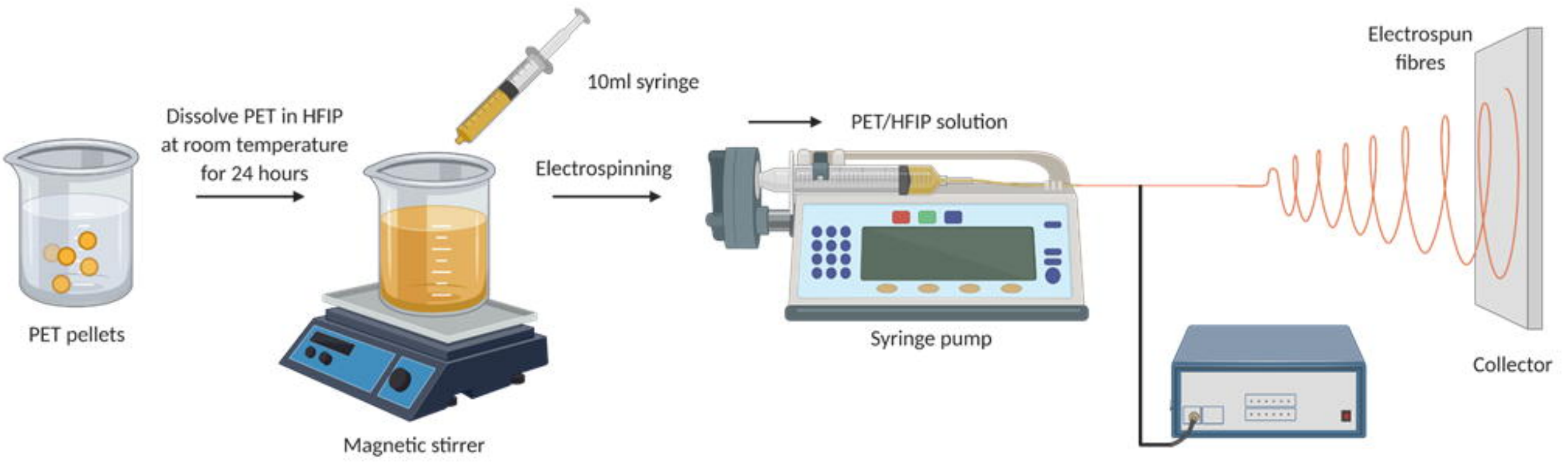

High voltage 
i.

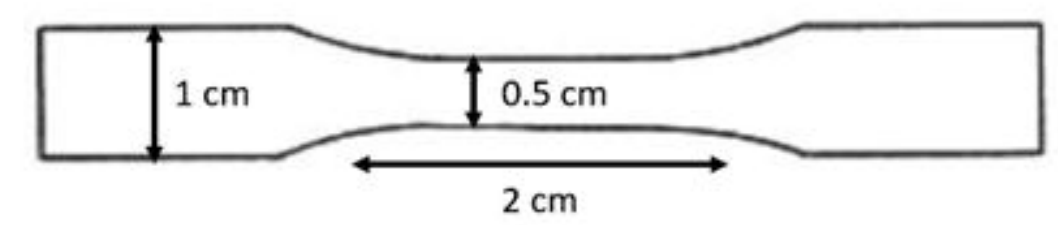

ii.

Stress vs Strain Curve

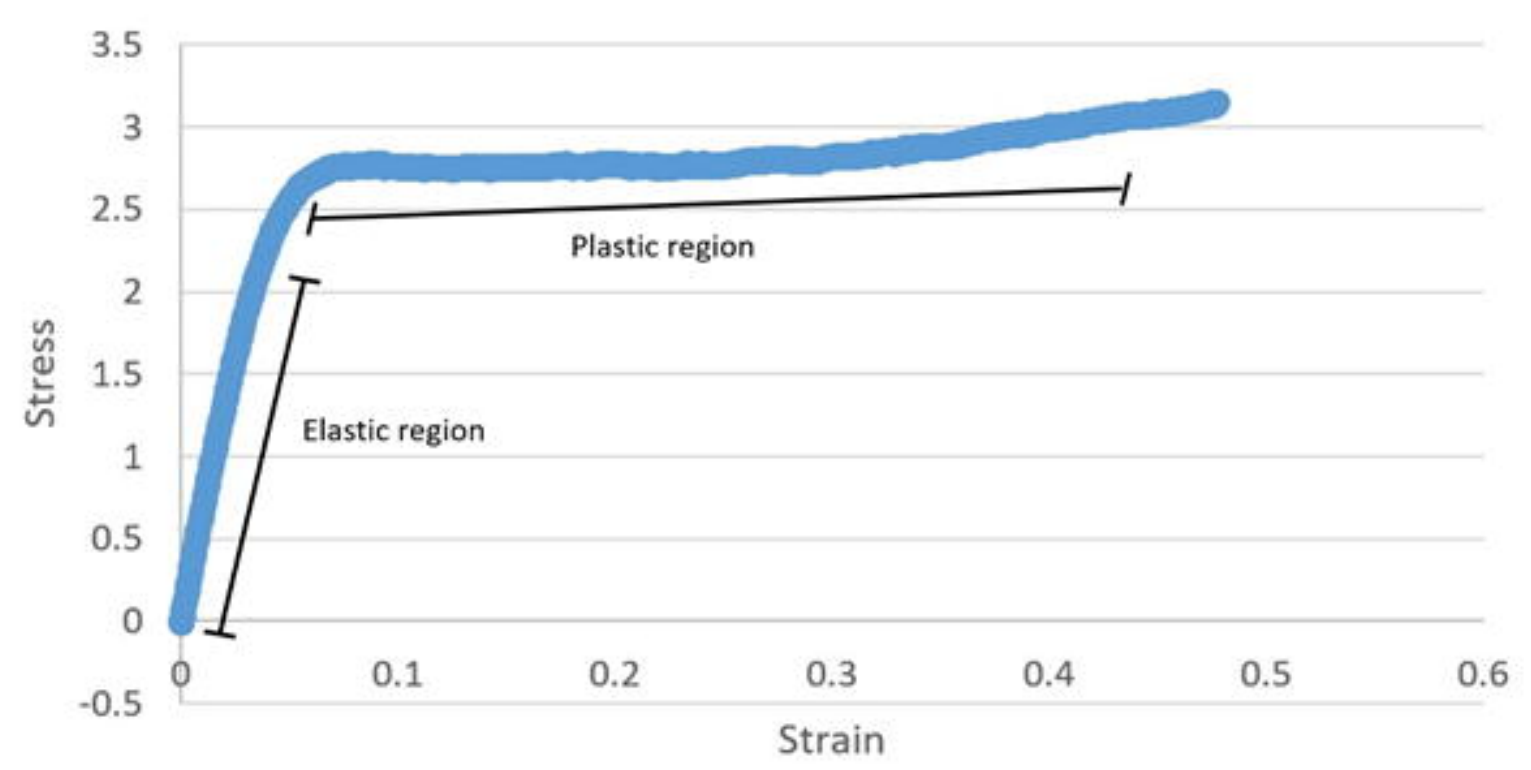


i.

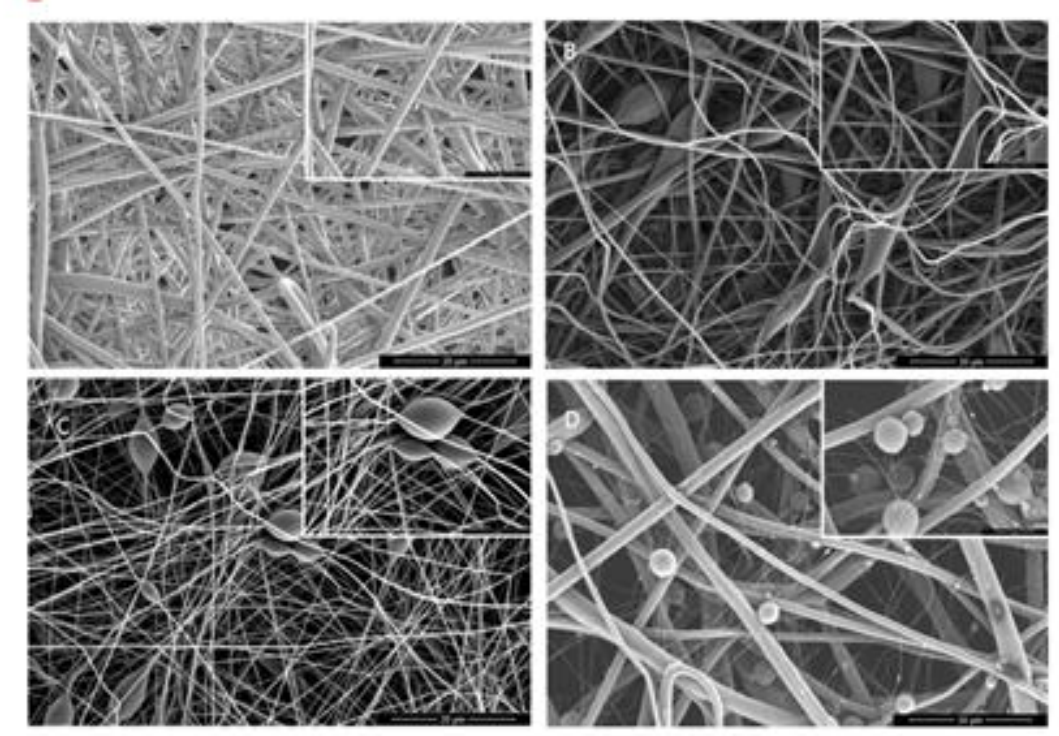

ii.

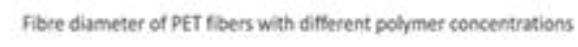

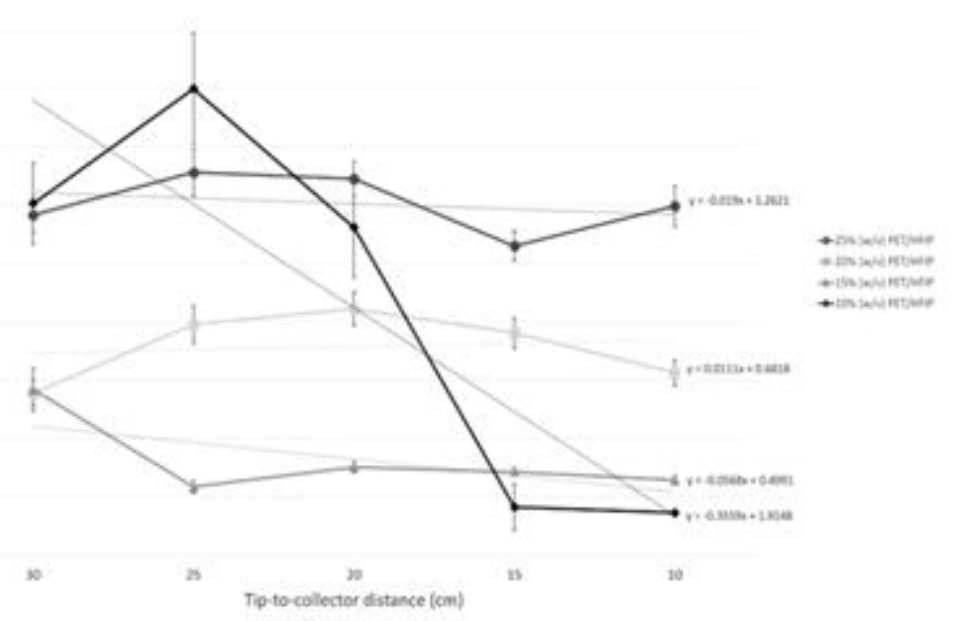

iii.

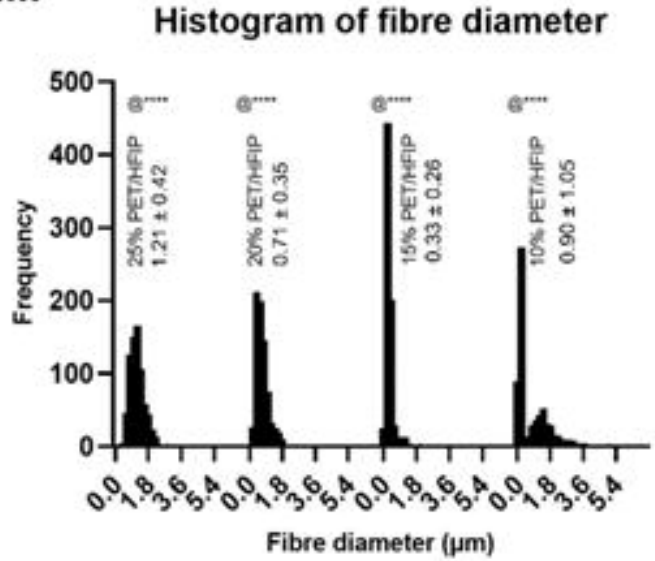

iv.

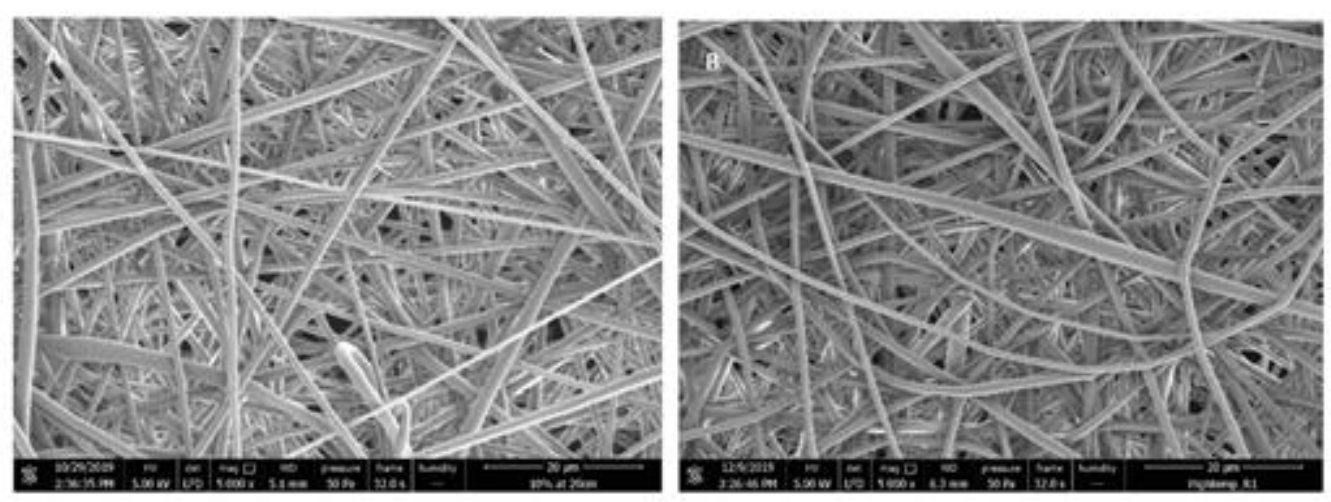


i.

$20 \%$ (w/v) PET/HFIP

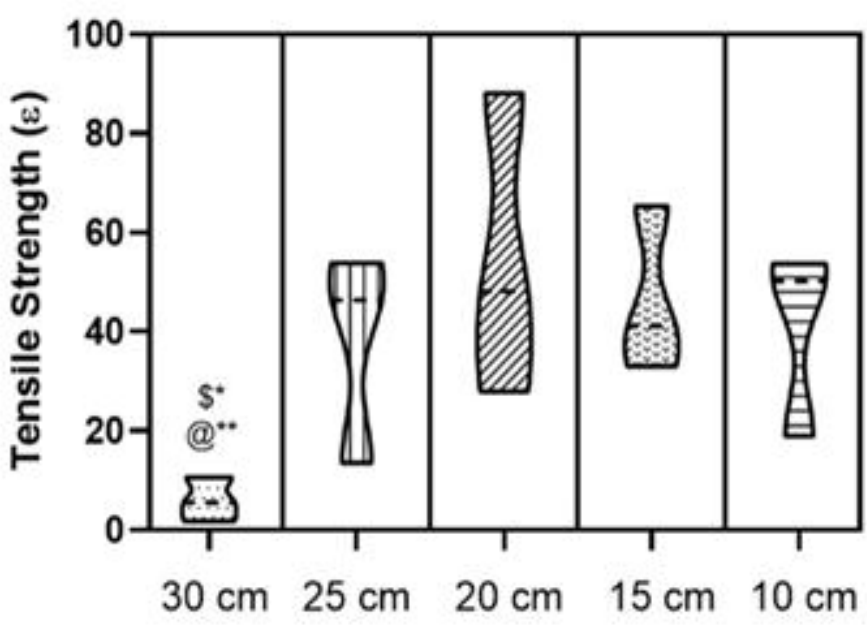

Tip-to-collector Distance

ii.

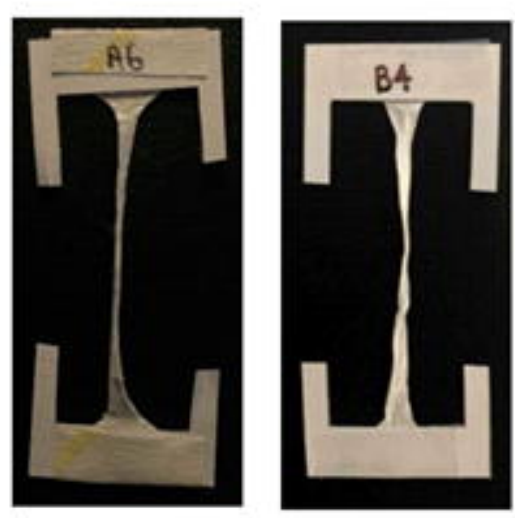

$25 \%$ (w/v) PET/HFIP

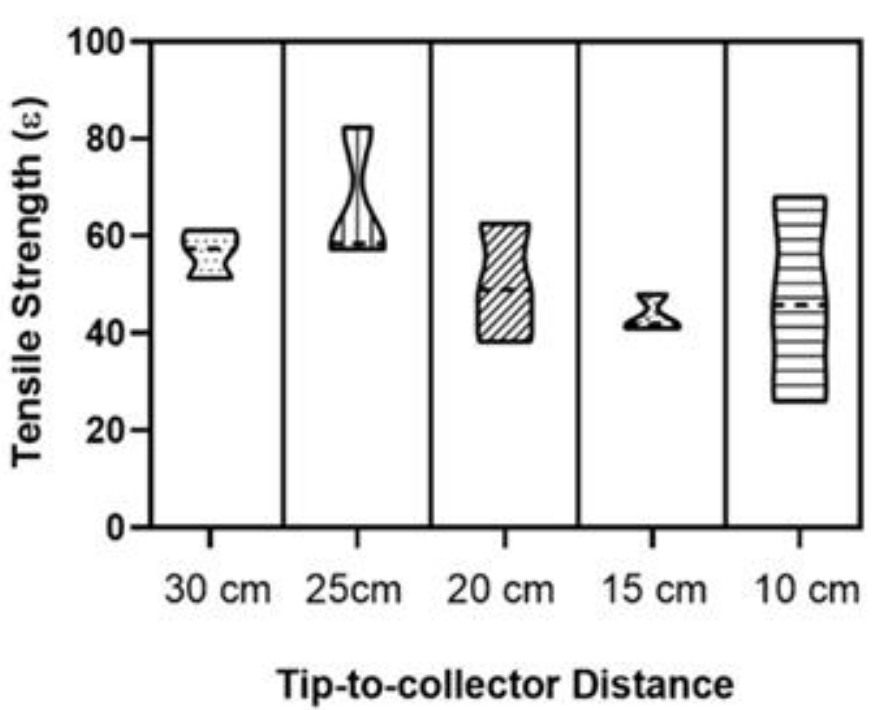

iii.
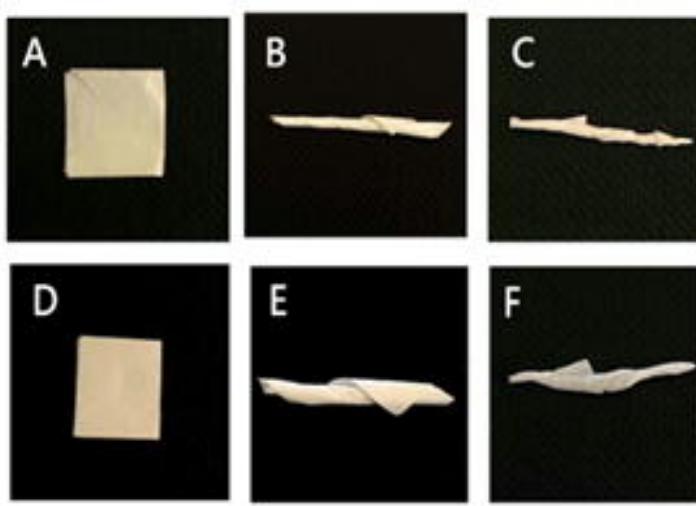

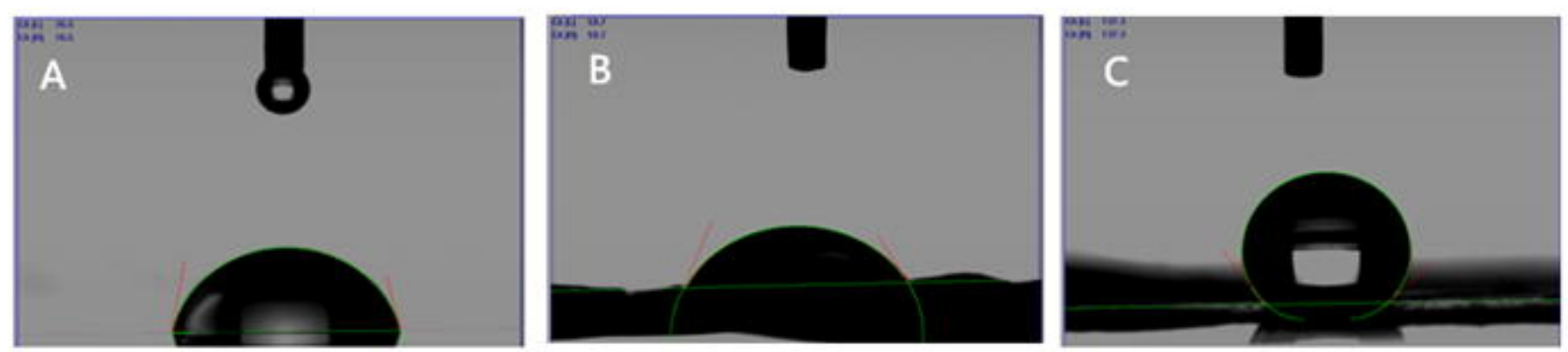

WCA comparison between planar and membrane surfaces

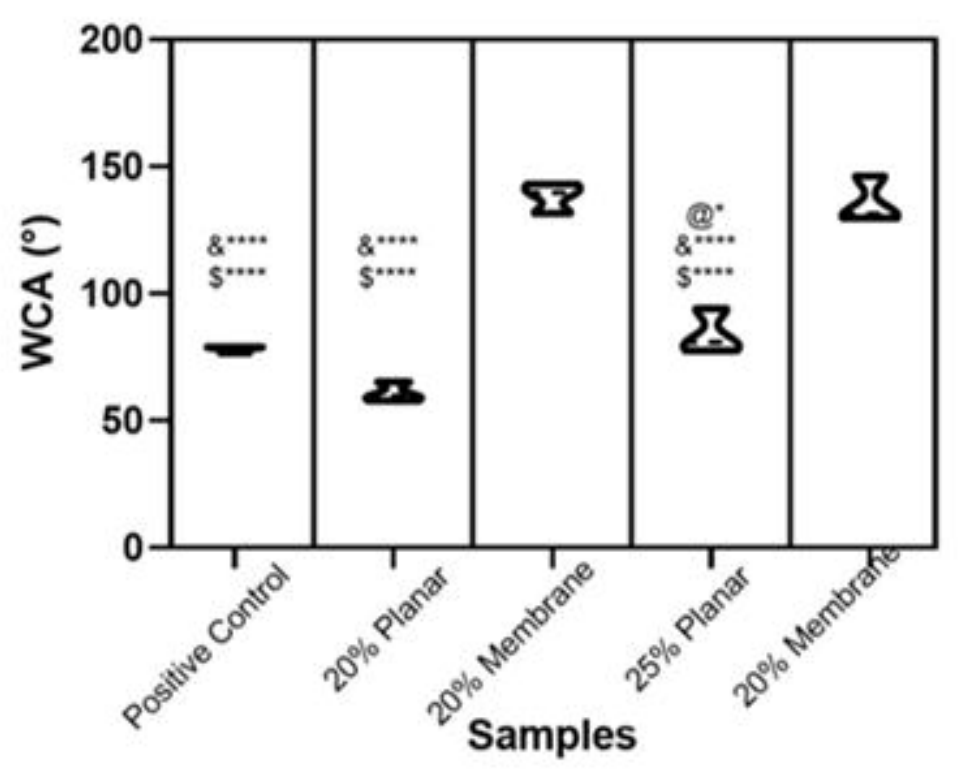




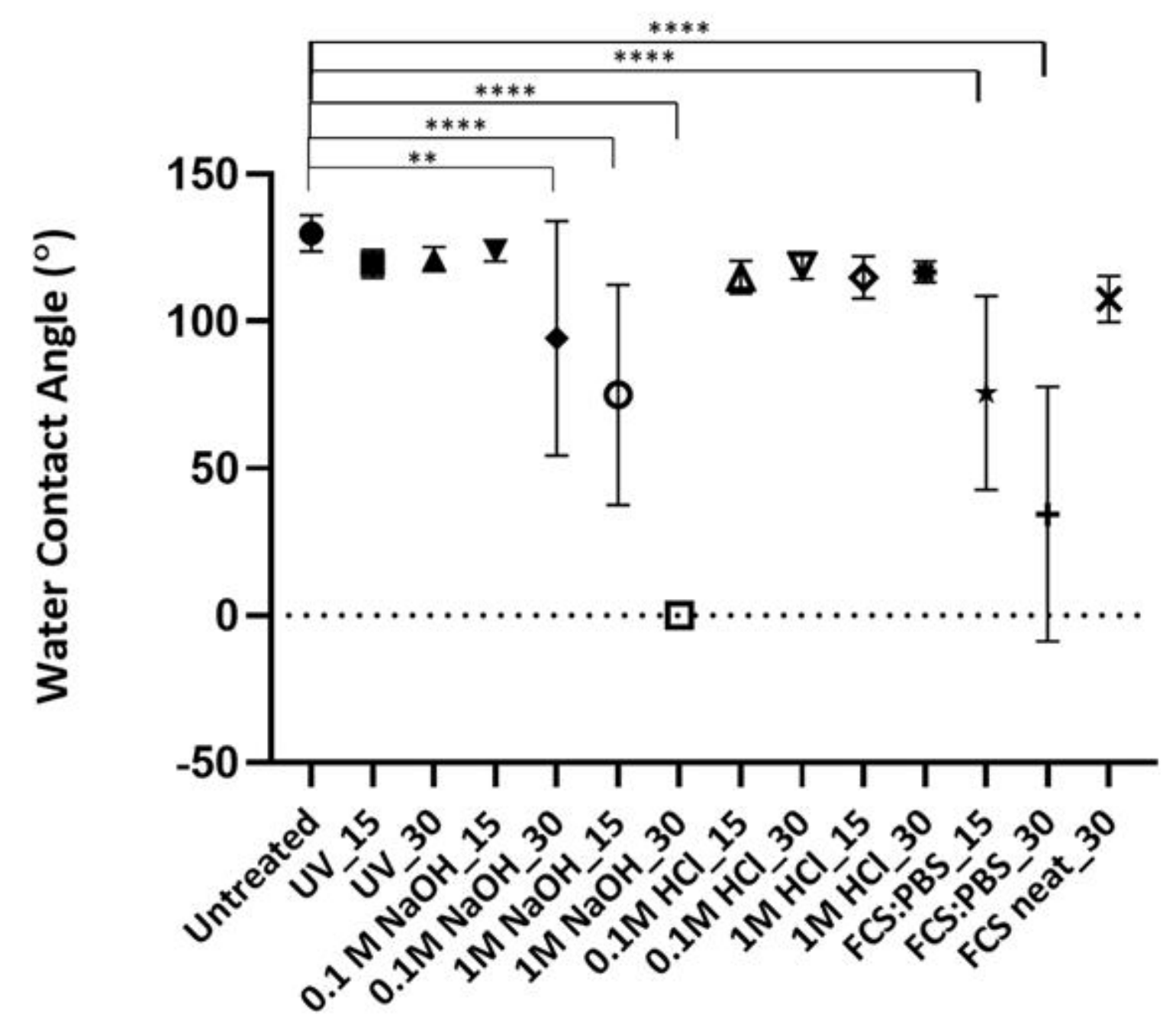

Surface treatments 


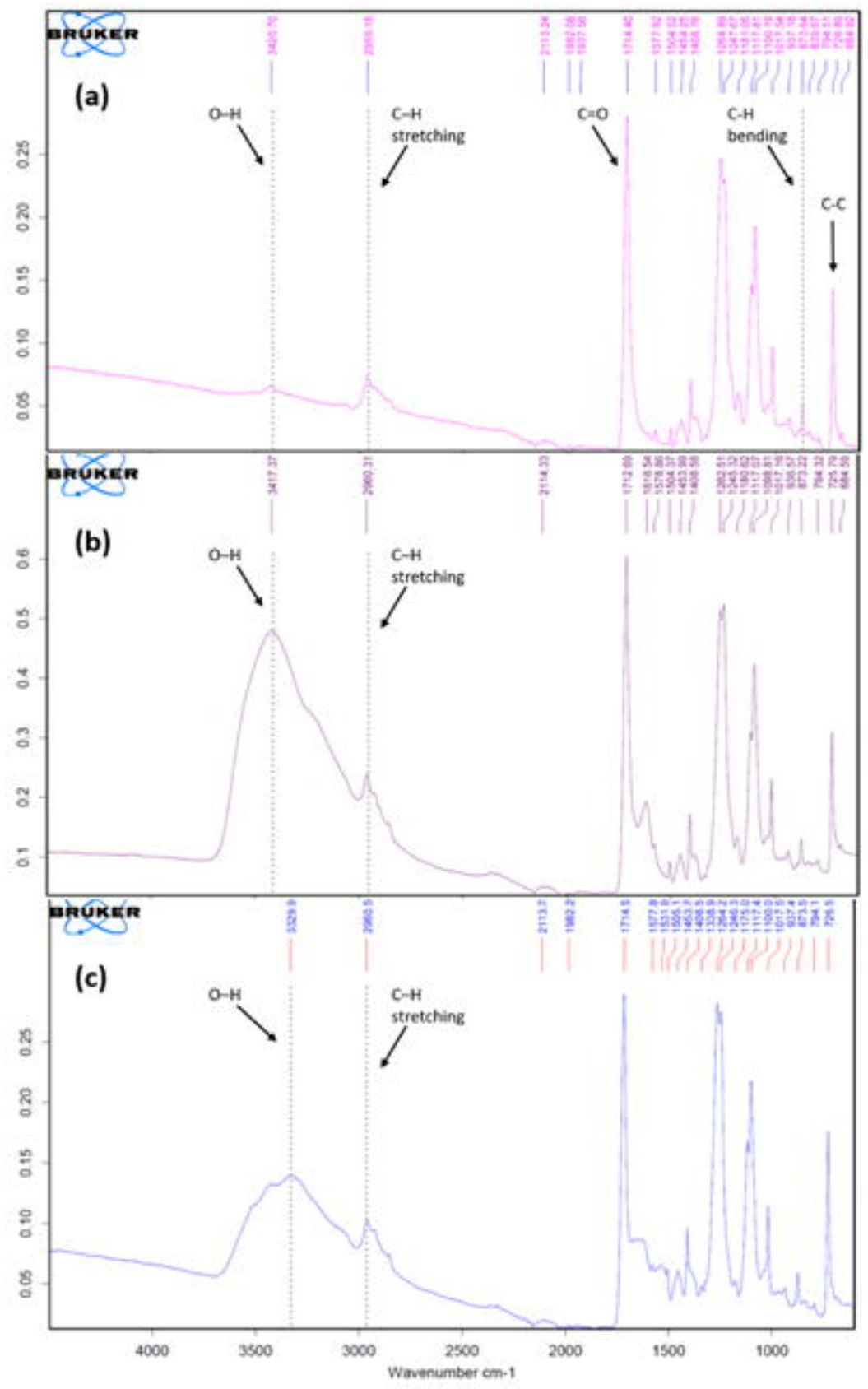



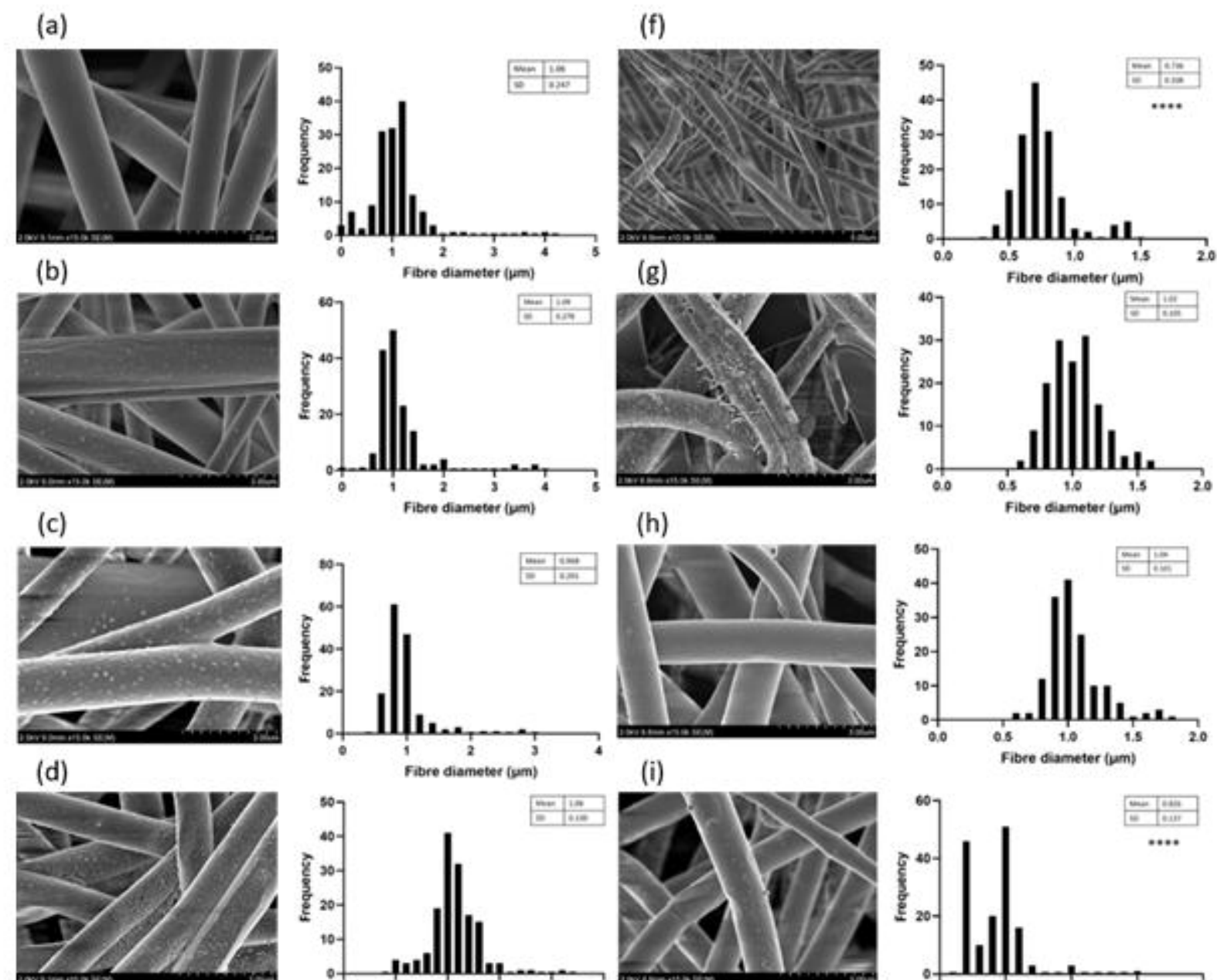

(h)
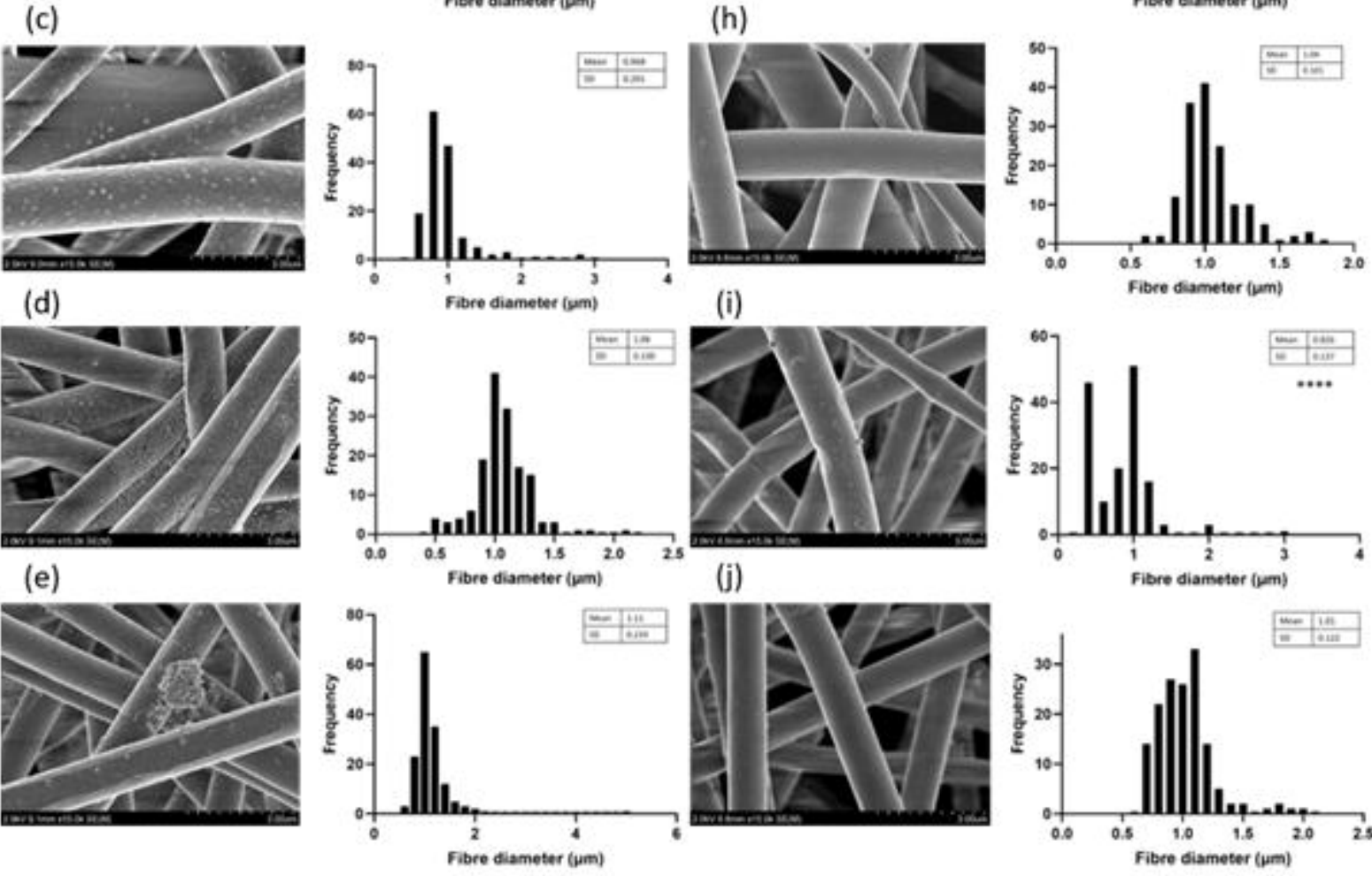
i.

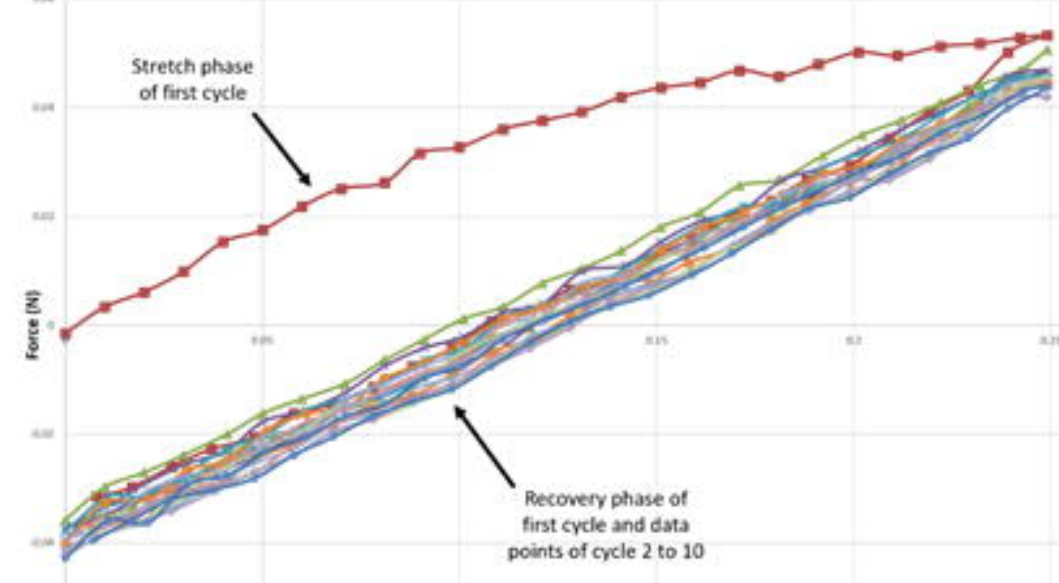

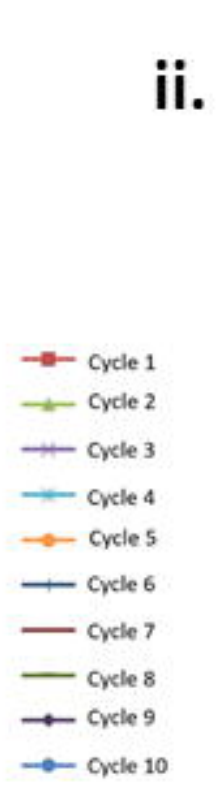

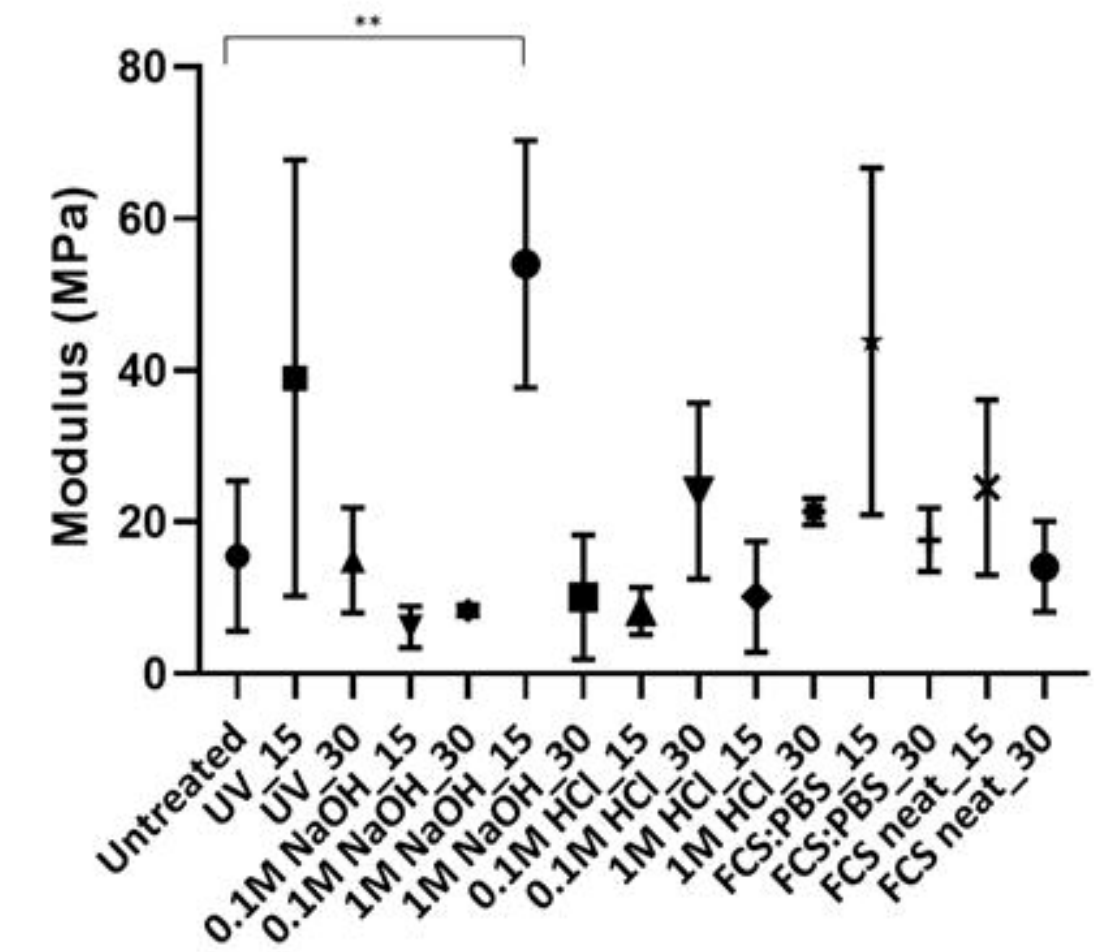

Surface treatments 


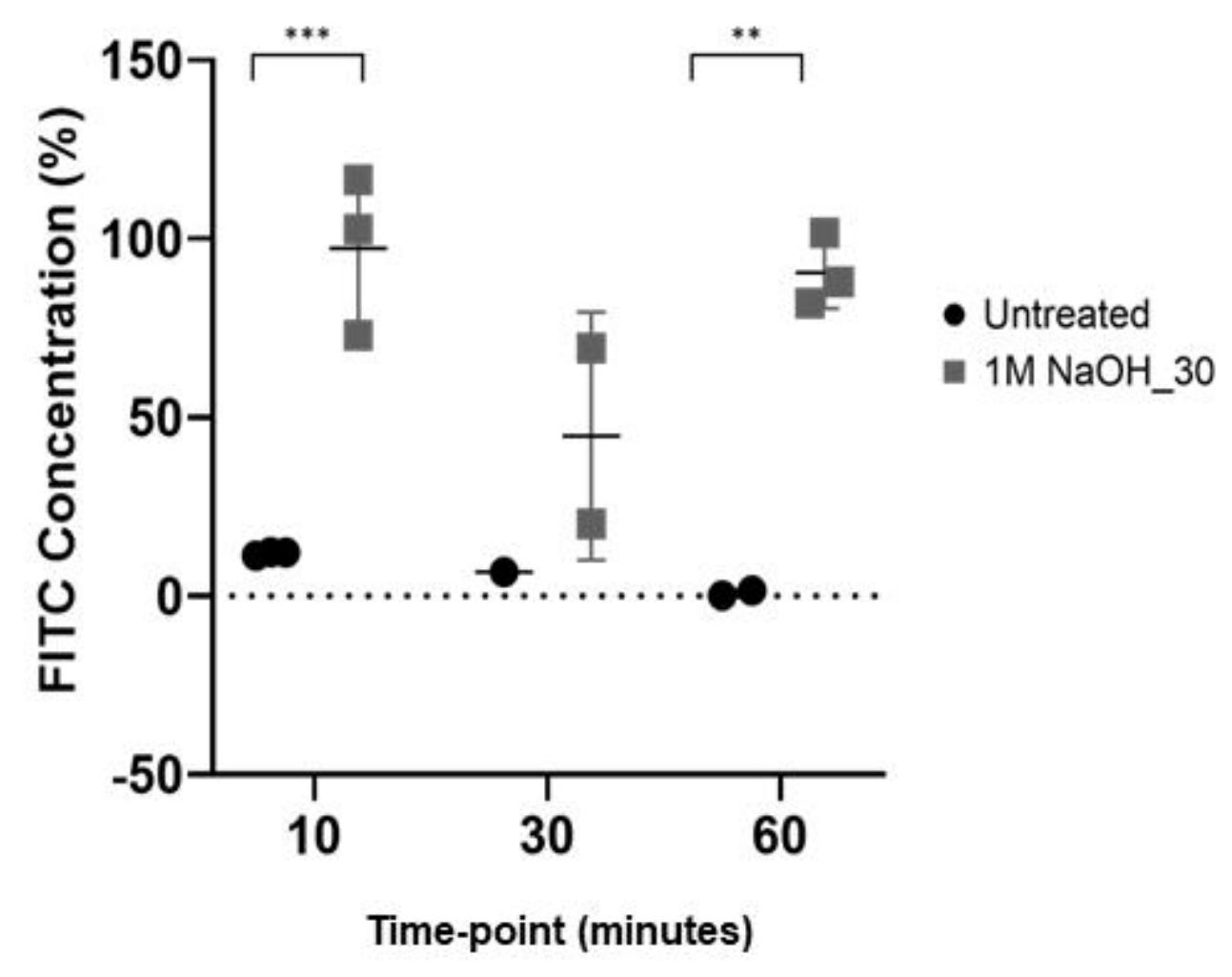

